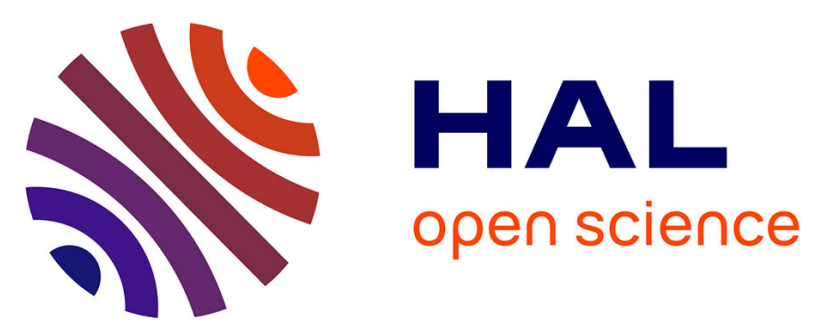

\title{
Intra- and inter-individual changes in little penguin diving and isotopic composition over the breeding season
}

Françoise Amélineau, Claire Saraux, Yan Ropert-coudert, Akiko Kato, Keith Hobson, Ben Raymond, Ilka Zimmer, André Chiaradia

\section{- To cite this version:}

Françoise Amélineau, Claire Saraux, Yan Ropert-coudert, Akiko Kato, Keith Hobson, et al.. Intraand inter-individual changes in little penguin diving and isotopic composition over the breeding season. Marine Biology, 2021, 168 (5), 10.1007/s00227-021-03867-2 . hal-03191780

\author{
HAL Id: hal-03191780 \\ https://hal.science/hal-03191780
}

Submitted on 20 Apr 2021

HAL is a multi-disciplinary open access archive for the deposit and dissemination of scientific research documents, whether they are published or not. The documents may come from teaching and research institutions in France or abroad, or from public or private research centers.
L'archive ouverte pluridisciplinaire HAL, est destinée au dépôt et à la diffusion de documents scientifiques de niveau recherche, publiés ou non, émanant des établissements d'enseignement et de recherche français ou étrangers, des laboratoires publics ou privés. 
3 Françoise Amélineau ${ }^{1, * * *}$, Claire Saraux ${ }^{2, * *}$, Yan Ropert-Coudert ${ }^{3}$, Akiko Kato ${ }^{3}$, Keith A.

51 Ecole Normale Supérieure de Lyon, 46 Allée d'Italie, 69007 Lyon, France

62 IPHC, CNRS, Université de Strasbourg, UMR 7178, Département d'Ecologie, Physiologie et Ethologie,

7 Strasbourg, France

83 Centre d'Etudes Biologiques de Chizé, CNRS UMR 7372 La Rochelle Université, 79360 Villiers-en-

9 Bois, France

104 Department of Biology, Western University, London, Ontario, Canada N6A 5B7

115 Australian Antarctic Division, Department of Agriculture, Water, and the Environment, Kingston, TAS

127050, Australia

136 Institute for Marine and Antarctic Studies, University of Tasmania, Hobart, TAS 7001, Australia

147 Asters - Conservatoire d'Espaces Naturels de Haute-Savoie, 38 rue de l'Annexion 74700 Sallanches,

15 France

168 Conservation Department, Phillip Island Nature Parks, PO Box 97, Cowes, Vic. 3922, Australia

$17 *$ Present address: Norwegian Polar Institute, Fram Centre, 9296 Troms $\varnothing$, Norway

$18 * *$ These authors contributed equally

$19 * * *$ Correspondent author: achiaradia@penguins.org.au

20 Keywords: stable isotopes, dive rate, diving efficiency, foraging behaviour 
22 Abstract: Seabirds allocate different amounts of energy to reproduction throughout the breeding season, depending on the trade-off between their own needs and those of their chicks and/or changes in environmental conditions. Provisioning parents therefore modulate their foraging behaviour and diet accordingly. However, for diving seabirds, many studies have extrapolated from individuals monitored over a short period and then assumed the observed patterns were representative of the birds' foraging

27 activity over the entire breeding stage/season. To address this shortcoming, we monitored continuously the 28 diving performance and isotopic composition of ten male little penguins from incubation to chick 29 fledging. Simultaneously, isotopic composition was examined using $\delta^{15} \mathrm{~N}$ and $\delta^{13} \mathrm{C}$ values from whole 30 blood samples collected every three weeks. Birds dived more frequently but performed shallower and 31 shorter dives as the season progressed. The guard period was especially different, with birds spending a 32 consistently smaller proportion of time at the bottom and performing fewer prey pursuits, compared to 33 other periods. Isotopic composition varied less within the season, although there was a slight tendency for $34 \delta^{15} \mathrm{~N}$ values to decrease through time. Finally, isotopic values were highly repeatable within individuals, 35 suggesting that individuals specialized on different prey and in different areas. Diving was less repeatable 36 within individuals but still explained a small but significant part of the variance in blood isotopic values. 37 Our results suggest that it is important to take into account individual variability over the course of the 38 breeding season, as well as timing of bio-logger deployment within a stage when designing bio-logging 39 studies. 


\section{Introduction}

Organisms face a trade-off in allocating energy to diverse functions, such as growth, selfmaintenance or reproduction (Stearns 1992). Such trade-offs will be exacerbated when food resources are limited. In this case, energy allocation should depend on life history strategy, with long-lived species favouring adult survival and future breeding opportunities and short-lived species favouring the current breeding attempt (Stearns 1992). As foraging behaviour represents an energetic investment to move in the environment, detect prey and handle it before gaining new energy (Bell 1991), it should vary both according to the endogenous needs of the organisms and the exogenous variation of food resources. In particular, within one breeding season, foraging should adjust to short-term variation in energy availability depending on environmental conditions, and in energy demand with offspring age and needs (Martin 1987; Erikstad et al. 1997). These within-individual variations in behaviour according to environmental fluctuations are an expression of phenotypic flexibility (Piersma and Drent 2003).

Seabirds are particularly suited to studies of foraging flexibility. Most of them are long-lived, so that energy allocation to adult survival should be less flexible, and changes in energy availability should be translated mostly in the amount of energy allocated to reproduction. Most seabirds exhibit bi-parental care (Lack 1968), so that both sexes are involved in incubation and chick-rearing, but not necessarily equally (Fasola and Saino 1995; Saraux et al. 2011a). For most seabirds, during the incubation and guard stages, one parent stays in the nest, incubating eggs or guarding chicks (i.e. the guard stage), while the partner forages at sea. During post-guard stage, both parents forage and return to feed the chicks that are left alone most of the time (Schreiber and Burger 2001). Energy demand varies with the phase of the breeding season, and so foraging constraints may not be the same when the birds have eggs, young or older chicks (Erikstad et al. 1997). Central place foraging may force seabirds to consume only those prey that are available within their foraging zone (but see Schreiber and Burger 2001). In some species, adults can make short trips to feed their chicks and longer trips to feed themselves (Chaurand and Weimerskirch 1994; Weimerskirch et al. 1997; Ropert-Coudert et al. 2004; Saraux et al. 2011b), resulting in diet segregation between chicks and adults (Davoren and Burger 
1999; Wilson et al. 2004; Alonso et al. 2012; Chiaradia et al. 2012). Additionally, the energy demand of the chicks increases with chick age in terms of meal size, while it may decrease in terms of feeding frequency (Chiaradia and Nisbet 2006). How seabirds adjust their foraging behaviour in response to these different constraints within a breeding season is an important question to understand their foraging flexibility, which is at the core of a better understanding of organism evolution (Piersma and Drent 2003)

In recent years, these questions have been addressed to some degree thanks to the development of biologgers (Ropert-Coudert et al. 2012). In most cases, birds are equipped during one or a few consecutive trips at sea to limit disturbance, and also because of limited battery life and/or memory of small data loggers (Takahashi et al. 2003), despite massive advances in this domain over the past decades. Such an approach implicitly assumes that data collected over a short period are representative of the whole breeding stage. That is, the foraging activity of each individual is sufficiently consistent within a breeding stage, so that intra-individual variability has no influence on the foraging behavior. However, foraging effort may change within breeding stages. For example, in African penguins Spheniscus demersus, adults perform longer foraging trips when chicks are older (Wilson and Wilson 1990) and flight velocity is higher at the beginning of incubation compared to late incubation in wandering albatrosses Diomedea exulans (Salamolard and Weimerskirch 1993). Yet, these studies were not longitudinal: several individuals were equipped at different breeding stages, preventing these studies from determining foraging variability over time at the individual level. While increasing sample size could buffer individual differences, note that increasing sample size is not always an option in the field (ethics authorizations or simply logistical constraints. This variability may be particularly relevant when seabirds are used as bio-indicators of their ecosystems (Bost et al. 2009). Indeed, if foraging activity is not constant over the breeding season, timing of sampling may provide different, perhaps conflicting results. Plus, when the season advances, only successful birds can be sampled, so that if breeding failure probability is high, a bias might be introduced in the analysis, when comparing any incubating birds with only successful birds at the end of the breeding cycle. 
Most studies at population level do sample animals for a short period at any given breeding stage. Results are then extrapolated to the breeding stage at a population level. By doing that, we are overlooking within stage patterns or individual variability. But the question is whether individual variability within a stage was lower than variability among stages. In this context, we monitored the foraging activity of ten little penguins Eudyptula minor throughout most of their breeding season. Little penguins are iconic upper predators in southern Australia, especially the Bass Strait region where our study was based. They feed on small pelagic fish, krill, cephalopods, other crustaceans and jellyfish to a lesser extent (Chiaradia et al. 2012, 2016; Cavallo et al. 2018). During guard, they forage within less than $30 \mathrm{~km}$ from the shore, but during incubation and post-guard, birds can travel as far as $100 \mathrm{~km}$ from the colony (Sánchez et al. 2018). Our longitudinal design monitored the diving effort (using long-life time-depth recorders) and trophic levels exploited (using stable isotopes) of little penguins throughout almost the entire breeding season, and allowed us to test whether individuals have different strategies or change their foraging behaviour and diet. Such changes could be due to changes in provisioning requirements over the breeding season or in response to changes in the environment and prey distribution (e.g. prey depletion around the colony (Ashmole 1971)). Here, we tested whether pinpoint information represents the whole stage and what is the individual variability.

\section{Materials and methods}

\section{Study site and species}

The study was conducted in Phillip Island, Victoria, Australia (38 $\left.31^{\prime} \mathrm{S}, 145^{\circ} 09^{\prime} \mathrm{E}\right)$. Between 28,000 to 32,000 little penguins breed on the western end of the island (Sutherland and Dann 2012). The study site has ca. 100 nest boxes where penguins have been breeding since the 1970s (Chiaradia and Kerry 1999). Since 2000, all birds have been marked with subcutaneous passive transponder tags (Allflex, Capalaba, Australia) implanted between the scapulae (shoulder blades; (Chiaradia and Kerry 1999) either at fledging or when first encountered as adult in the study site. Sex was determined by bill measurements when the birds were first found in the colony as adults (Arnould et al. 2004) and confirmed by pairing data. Nest boxes are checked three times a week during the breeding season to 
determine the breeding success and phenology of birds (laying date, hatching date, start of post-guard, fledging date, ESM1). Individuals with transponders were detected in the nest using a purpose-built handheld transponder reader. Further, attendance data in the colony were recorded by an Automatic Penguin Monitoring System (APMS) located along the main path into the Penguin Parade study site (Kerry et al. 1993). The APMS has an electronic transponder reader that records the transponder identification, and time of a penguin crossing the reader (Robinson et al. 2005). Foraging trip duration could then be estimated from the combination of nest attendance, passages over the APMS and temperature and depth data from the loggers.

\section{Field protocol and Logger deployments}

During the 2008-2009 summer, ten males were equipped with time-depth recorders (G5, CEFAS Technology Limited, Lowestoft, UK; diameter: $8 \mathrm{~mm}$, length: $31 \mathrm{~mm}$, weight: $2.7 \mathrm{~g}$, i.e. about $0.3 \%$ of the bird's mass, recording 1 point every 2 seconds with a $0.03 \mathrm{~m}$ depth resolution and an accuracy of $1 \mathrm{~m})$ throughout the whole breeding season. We equipped only males to limit the numbers of confounding factors influencing diving behaviour. The loggers recorded pressure and temperature every two seconds between 4 am and $9 \mathrm{pm}$ (in order to save battery and memory space, as little penguins do not dive at night (Cannell and Cullen 1998)), for a period of 18-21 days per deployment. Because of limiting memory capacity and in order to cover the complete breeding season, loggers were replaced up to three times for each individual bird. Recordings covered incubation, guard and the beginning of post-guard. However, among the 40 deployments, eight of them did not provide data (loggers were either lost or encountered technical problems). No negative effect on penguin breeding success was detected ( $80 \%$ in our 10 studied birds versus $30 \%$ for that year in the colony). The recordings consequently did not cover the whole breeding period for all 10 penguins (details on each deployment are shown in ESM 1).

Loggers were attached to the feathers with Tesa tape (Hamburg, Germany) to minimize damages to the plumage and to allow for quick deployment and recovery (Wilson et al. 1997). They were the smallest loggers available at the time of the study, accounting for less than $1 \%$ of the birds' frontal 
area (see Ropert-Coudert et al. 2007). They were placed on the lower back of the birds in order to minimize the drag (Bannasch et al. 1994). Birds were weighed to the closest $10 \mathrm{~g}$ using a spring balance. At each recapture, birds were weighed and blood was sampled for stable isotope analysis. Total handling time per capture was less than 5 minutes.

\section{Stable isotope analysis}

Because loggers were deployed for 18-21 days, we performed stable isotope analyses of nitrogen $\left(\delta^{15} \mathrm{~N}\right)$ and carbon $\left(\delta^{13} \mathrm{C}\right)$ on whole blood samples rather than plasma (see Chiaradia et al. (2012) for details). For little penguins (mean male body mass in 2008: 1137 $\pm 5 \mathrm{~g}$, Saraux et al. 2011a), the halflife for turnover of carbon in whole blood is of the order of 16-17 days (based on Great Skua Catharacta skua; Bearhop et al. 2002; Carleton and Del Rio 2005). This suggests that blood isotope measurements of penguins integrated diet and physiology data over approximately one month (or two half-lives) prior to sampling, matching the time scale of logger deployments. Values of $\delta^{15} \mathrm{~N}$ and $\delta^{13} \mathrm{C}$ can be used to describe isotopic niches of the predator (Jackson et al. 2011). Tissue $\delta^{15} \mathrm{~N}$ is known to increase incrementally with trophic level (Fry 2006), while variations in $\delta^{13} \mathrm{C}$ can better reflect differences between inshore and offshore prey, $\delta^{13} \mathrm{C}$ being higher inshore (Hobson and Welch 1992). Whole blood was freeze-dried and then powdered. The extraction of lipids was considered unnecessary for blood samples, because the lipid component in blood is generally low but does depend on occurrence of recent feeding (Bearhop et al. 2000; Chiaradia et al. 2010). Further, mass C/N ratios were all below 3.5 (range: [3.35 - 3.47]), confirming the absence of need to correct for lipid contents in whole blood (Post et al. 2007). Finally, C/N ratios and individual mass did not vary over the course of the season (LMMS: $\mathrm{C} / \mathrm{N}$ ratio $\sim$ Julian date $+(1 \mid$ individual), $-0.0002 \pm 0.0002, \mathrm{P}=0.271, \mathrm{n}=32, \mathrm{~N}$ $=10$ individuals; mass $\sim$ Julian date $+(1 \mid \mathrm{ID}), 0.56 \pm 0.70$ g.day $^{-1}, \mathrm{P}=0.425, \mathrm{n}=43, \mathrm{~N}=10$ individuals), suggesting that individual condition did not change over the course of the breeding season.

Stable carbon and nitrogen isotope assays were performed on $1 \mathrm{mg}$ subsamples of homogenised materials by loading into tin cups and combusting at $1200^{\circ} \mathrm{C}$ in a Robo-Prep elemental analyser. Resultant $\mathrm{CO}_{2}$ and $\mathrm{N}_{2}$ gases were then analysed using an interfaced Europa 20:20 continuous-flow 
isotope ratio mass spectrometer (CFIRMS) with every five unknowns separated by two laboratory standards (baleen: BWB: $\delta^{13} \mathrm{C}=-20.18 \%, \delta^{15} \mathrm{~N}=+14.31 \%$; PRCgel: $\delta^{13} \mathrm{C}=-13.64 \%$ o, $\delta^{15} \mathrm{~N}=$ $+5.07 \%$ ). Based on replicate measurements of within-run standards, measurement error was estimated to be \pm 0.3 and $\pm 0.1 \%$ for $\delta^{15} \mathrm{~N}$ and $\delta^{13} \mathrm{C}$ measurements, respectively.

\section{Dive data analysis}

Upon recovery of the time-depth recorders, data were downloaded and depth data were analysed using purpose-written software in Igor Pro version 6.22A (Wavemetrics, Portland, Oregon). Depth data were first corrected for surface drift. Data were then automatically processed to provide an output file that summarizes the characteristics of each dive. We focused on those variables that best reflect the diving activity of little penguins at different scales (Kato et al. 2006). At the scale of individual dives, we calculated the following parameters: maximum depth reached for each dive, dive duration that starts and ends the first and last time that depth was $>1 \mathrm{~m}$, respectively; bottom duration calculated as the time spent around the maximum depth of the dive that starts and ends the first and last time the absolute value of the depth change rate was $<0.25 \mathrm{~m} / \mathrm{s}$, respectively, and which corresponds to the dive phase where the majority of prey are encountered (e.g. Ropert-Coudert et al. 2006); number of undulations during the bottom phase (Zimmer et al. 2010); and post-dive duration, which is the time spent at the surface between two dives during which penguins not only recover from the previous dive but also prepare the next dive via hyperventilation (Wilson 2003).

Dives were then classified as one of three different types: $\mathrm{V}$ dives, $\mathrm{U}$ dives and $\mathrm{W}$ dives according to bottom duration and the number of undulations (Wilson 1995). Dives for which the depth change rate never fell below $0.25 \mathrm{~m} / \mathrm{s}$ were considered $\mathrm{V}$ dives with no bottom phase. Other dives were separated according to the absence of undulations: $\mathrm{U}$ dives, or the presence of undulations: $\mathrm{W}$ dives.

Combining some of these parameters, we also calculated the dive efficiency, following Ydenberg and Clark (1989), through the proxy of bottom use and dive use:

Bottom use $=\frac{\text { Bottom duration }}{(\text { Dive duration }+ \text { Postdive duration })} ;$ Dive use $=\frac{\text { Dive duration }}{(\text { Dive duration }+ \text { Postdive duration })}$ 
For these two metrics, only dives with a post dive duration $<100 \mathrm{~s}$ were considered, that is, dives that belong to a bout in little penguins (Chiaradia et al. 2007). Note that bottom use was not estimated for $\mathrm{V}$ dives (no bottom phase in these dives).

Because the aim of this study was to estimate how diving and foraging vary according to the season and the advancement in breeding, we decided to work at the temporal scale of the day.

Therefore, all parameters mentioned above were aggregated per day, as follow:

- Mean maximum depth (MD),

- mean duration of a dive per day,

- mean post-dive duration (considering only dives that belong to a bout),

- mean dive use per day (considering only dives that belong to a bout),

- mean bottom duration (excluding $\mathrm{V}$ dives) per day,

- mean bottom use (of dives that belonged to a bout, excluding $\mathrm{V}$ dives) per day,

- total number of undulations (summed over all dives) per day.

Further, as penguins dive and forage only during daylight (Cannell and Cullen 1998), we estimated the duration of diving activity per day as the duration between the first dive of the day and the last one $($ mean $\pm \mathrm{SD}=14 \mathrm{~h} 15 \mathrm{~min} \pm 37 \mathrm{~min}$, range $=[12 \mathrm{~h} 49 \mathrm{~min}-16 \mathrm{~h} 32 \mathrm{~min}])$. The dive frequency (number of dives per hour) was then estimated by dividing the number of dives per day by the duration of diving activity. Finally, the proportions of $\mathrm{U}, \mathrm{V}$ and $\mathrm{W}$ dives per day were also estimated.

\section{Statistical analyses}

All analyses were performed using R 3.5.0 (R Core Team 2018). The level of significance in all tests was set to $\mathrm{P}<0.05$.

First, a Principal Component Analysis (PCA) was performed using individual * days as objects and all 12 previously described diving parameters as descriptors to summarize all information and describe relationships between descriptors (separate analyses on the 12 parameters can be found in supplementary material; see ESM2). 
We then investigated whether results from this PCA varied along the breeding season. Because diving could vary according to parental needs, chick age and needs but also to changes in the environment (Bertram et al. 1996; Shaffer et al. 2003; Le Guen et al. 2018), we looked at two different variables. First, we calculated a date relative to hatching date (RHD) in order to have the same timescale with the origin at hatching for all birds (as the duration for the incubation varied between birds: mean \pm SD: $36.7 \pm 2.4$ days, range: $[34-41$ days]). Negative values of RHD correspond to the remaining time of incubation, while positive values represent chick age in days. Second, because breeding is not synchronised in little penguins, we considered the Julian calendar date as an explanatory variable, on top of RHD. However, computing Variance Inflation Factor (VIF) showed that these two variables (RHD and Julian calendar dates) were highly correlated ( $\mathrm{r}=0.94, \mathrm{P}<0.001)$, so that they could not be investigated simultaneously in the models and one of the two covariates had to be dropped (Zuur et al. 2007). Linear mixed effect models (LMM) were run to explain the first two principal components of the PCA, using Julian calendar date and breeding stage as explanatory variables and the individual as a random factor to account for non-independent data. Similar results were obtained when running models with chick age and breeding stages and can be seen as independent panels in the figures, but statistics are only presented in supplementary material for clarity purposes (ESM3). Julian calendar dates were either used as unchanged or squared to test for a potential quadratic effect of this variable, i.e. to look for an optimal period or for a maximal foraging effort.

Finally, because individuals were monitored longitudinally over the breeding season, we investigated both the within- and among-individual variability in diving performances through two methods. First, we estimated the repeatability of diving characteristics (as estimated by the first two principal components of the PCA) using an ANOVA according to (Nakagawa and Schielzeth 2010). Repeatability was estimated as $r=\frac{s_{A}^{2}}{s^{2}+s_{A}^{2}}$,

where $\mathrm{s}^{2}$ is the within-individual variance component (mean sum of squares within groups, $\mathrm{MS}_{\mathrm{W}}$ ) and $s_{A}^{2}$ is the among individual variance component, such as

$s_{A}^{2}=\frac{M S_{A}-M S_{W}}{n_{0}}$, 
$\mathrm{n}_{0}$ being the number of replicates and $M S_{A}$ being the mean sum of squares among individuals. Because, individuals were not monitored in the same number of days, $\mathrm{n}_{0}$ was estimated as

$n_{0}=\frac{1}{N-1}\left(n-\frac{\sum_{i=1}^{N} n_{i}^{2}}{n}\right)$

where $\mathrm{N}$ is the number of individuals, $\mathrm{n}$ the total sample size, and $\mathrm{n}_{\mathrm{i}}$ the sample size of the $\mathrm{i}^{\text {th }}$ individual, accounting for overestimation of variance among smaller groups compared to larger groups. The higher the value of $r$ the more repeatable diving is within individuals, which would here mean that individuals display consistent differences in their diving characteristics. Second, we looked at the effect of breeding stage on PCA results per individual using separate linear models and quantified the proportion of individual models giving the same result as the general trend observed over all individuals.

Finally, we investigated inter-individual differences in isotopic values using repeatability analyses after ANOVA (see above). Changes in isotopic values along the season were investigated using a LMM with chick age or Julian calendar date as explanatory variables and the individual identity as a random effect to account for the non-independence of the data. Because blood samples were not performed exactly at the same time relative to chick age and breeding stages for all individuals, we preferred using chick age over breeding stage in this analysis. Further, to study whether isotopic values were affected by diving characteristics, we averaged the principal component values over the 28 days preceding blood sample. Given that individuals were sampled repeatedly ( 1 to 4 times) along the season, each data point was not independent. However, since both the variances in isotope values and diving characteristics resulted from the combination of inter-individual differences and withinindividual differences, controlling for individual ID as a random variable in this model masks the variability in isotope values between individuals that could be explained by inter-individual differences in diving. Therefore, we investigated the variance in $\delta^{15} \mathrm{~N}$ or $\delta^{13} \mathrm{C}$ values explained by PC1 and PC2 using a linear model and compared the results with a linear mixed model with the individual as a random effect, and discuss the differences between both approaches. 


\section{Results}

Over a two-month period, from incubation to the beginning of post-guard stage, diving data were recorded for an average of 24 days at sea (range: 7 to 37 days) for each penguin. Two birds failed early in the breeding season. A summary of the logger deployment for each individual is available in ESM 1.

\section{Changes of diving parameters along the season}

The first two components of the PCA run over daily values of all 12 diving parameters explained $75 \%$ of the variance ( $44.5 \%$ and $30.4 \%$, respectively; Figure 1 ). The first axis clearly contrasted days with long and deep dives (positive PC1) to days with more frequent and shorter dives and a high proportion of $\mathrm{V}$ dives (negative PC1). PC1 can thus be considered as an index of "depth use". The second axis highlights the opposition between days with high proportion of U dives (negative PC2) versus days with a high proportion of $\mathrm{W}$ dives, a high number of undulations and a high bottom use (positive PC2). This axis is hereafter referred to as "bottom activity" index.

Looking at how daily values were scattered in this two-dimension plan, diving parameters overlap between breeding stages, but also according to chick age and Julian dates (Figure 2). Still, diving appeared less variable during guard than in the other two breeding stages. Looking at the effect of breeding stage only, depth use index (PC1) was lower during post-guard than during incubation and guard (LMM: $\mathrm{n}=243, \mathrm{~N}=10$ males, $-1.36 \pm 0.34, \mathrm{P}<0.001$ and $-0.95 \pm 0.39, \mathrm{P}=0.041$, respectively, using Tukey post-hoc tests; Figure 3A). Similarly, depth use index decreased with the Julian calendar date (LMM: $\mathrm{n}=243, \mathrm{~N}=10$ males, $-0.04 \pm 0.01, \mathrm{P}<0.001$, Figure $3 \mathrm{C}$ ). In other words, penguins dived more frequently with a higher proportion of short and shallower $\mathrm{V}$ dives as the season progressed, as confirmed by the separate analyses of single dive parameters (ESM2). Bottom activity index (PC2) was lower in guard than in incubation and post-guard (LMM: $n=243, \mathrm{~N}=10$ males, $-1.34 \pm 0.29, \mathrm{P}<0.001$ and $-1.73 \pm 0.34, \mathrm{P}<0.001$ after Tukey post-hoc tests; Figure 3D). Similarly, we observed a quadratic effect of the Julian calendar date on bottom activity index. Estimating the $\mathrm{a}$ and $\mathrm{b}$ coefficients of the relationship, PC2 $\sim \mathrm{a} *$ date ${ }^{2}+\mathrm{b} *$ date, we found that the quadratic relationship was centered on the date $=-\mathrm{b} / 2 \mathrm{a}=314$ (i.e. the $10^{\text {th }}$ of November). After 
centering the Julian date on 314, we found a significant quadratic effect of Julian date on (LMM: $n=$ $243, \mathrm{~N}=10$ males, $0.002 \pm 0.000, \mathrm{P}<0.001$, Figure $3 \mathrm{~F}$ ), with lower values in the middle of the season. This means that birds performed a higher proportion of $U$ dives with a low bottom use and low number of undulations during guard, compared to incubation and post-guard, as confirmed by the analysis of single diving parameters (see ESM2).

\section{Individual differences in diving parameters}

Diving parameters overlapped strongly among individuals, with some individuals showing a high variability (e.g. 3013 or 3089; Figure 4). Nevertheless, significant differences in diving parameters were highlighted between individuals in both depth use and bottom activity indexes, which displayed a moderate to low repeatability (ANOVAs, $\mathrm{P}<0.001, \mathrm{r}=0.35$ and $\mathrm{r}=0.21$, respectively). This suggests potential differences in individual strategies but also a high variability between trips by the same individual. Individual data (Figure 5) showed that high variability in diving could be due to differences between the 3 breeding stages (e.g. 3089 showed distinct diving patterns in incubation, guard and postguard) or simply a high variability in diving even within a given stage (e.g. 3013 was monitored only during incubation but was the most variable individual).

Discarding individuals that were monitored only over incubation, we ran seven separate individual models explaining either depth use or bottom activity indices by breeding stage to see whether the overall pattern held for each individual (Tables $1 \& 2$ ). First, the general pattern showing that individuals performed more frequent but shorter and shallower dives as the season progressed, especially in post-guard, held true in only 2 out of 5 birds. One bird (4026) showed a reverse pattern with depth use index being higher in post-guard than in incubation. That is, it performed less frequent but longer deeper dives during post-guard than incubation. All other instances of individual depth use index not following the general pattern were due to the same two birds (3053 and 3072), for which depth use index was lower in guard than incubation but increased again after in post-guard. However, the fact that birds performed a higher proportion of $U$ dives with a low bottom use and number of undulations during guard, compared to incubation and post-guard held true in most birds (Table 2). Indeed, bottom activity index was lower in guard than in incubation in 5 out of 6 birds (note that one 
of the five birds only showed almost significant results at $\mathrm{P}=0.06$ ), than in post-guard in 2 out of 4 birds (with again one result being almost significant at $\mathrm{P}=0.06$ ). Bottom activity index did not vary between incubation and post-guard in 4 out of 5 birds. The instances where the general pattern in bottom activity index was not verified were due mostly to one bird: 3024, in which bottom activity index increased along the season, instead of showing a quadratic curve.

\section{Variations of isotopic composition over the breeding season and between individuals}

Two individuals had high $\delta^{15} \mathrm{~N}$ values (individuals 3013 and 4026; Figure 6) compared to the others. Using repeatability analyses, we showed that the inter-individual variance was much more important than intra-individual variance for $\delta^{15} \mathrm{~N}$ values (ANOVA, $\mathrm{P}<0.001$ and $\mathrm{r}=0.87$ ), suggesting that individuals might target different prey or feed in areas with different $\delta^{15} \mathrm{~N}$ baseline values. Interindividual variability in $\delta^{13} \mathrm{C}$ values was also highly significant (ANOVA: $\mathrm{P}<0.001$ ), although the repeatability was slightly lower $(\mathrm{r}=0.61)$ showing that intra-individual variation was also quite high. This suggests individual little penguins use different foraging areas.

Further, there were no significant changes in mean isotopic values over the breeding season (Figure 7), although $\delta^{15} \mathrm{~N}$ values tended to decrease along the season (LMMs, $\mathrm{n}=32, \mathrm{~N}=10$ males, $\mathrm{P}=0.07$ and $\mathrm{P}=0.08$ for chick age and Julian date, respectively).

Finally, $\delta^{15} \mathrm{~N}$ values were not related to depth use index but tended to increase with bottom activity index (LM: $\mathrm{n}=32, \mathrm{P}=0.133$ and $\mathrm{P}=0.062$, respectively; Figure 8). Values of $\delta^{13} \mathrm{C}$ decreased with depth use index and tended to increase with bottom activity index (LM: $\mathrm{n}=32, \mathrm{P}=0.036$ and $\mathrm{P}=$ 0.053, respectively; Figure 8). In other words, a higher bottom activity index (i.e. high bottom use, high number of undulations and low proportion of $\mathrm{U}$ dives) tended to result in higher $\delta^{15} \mathrm{~N}$ and $\delta^{13} \mathrm{C}$ values, while a low depth use index (i.e. less frequent deeper and longer dives) resulted in a decrease in $\delta^{13} \mathrm{C}$, as confirmed by the separate analyses of single dive parameters (see ESM2). Note, however, that if we include the individual as a random effect in these models, these effects become non- 
significant $(\mathrm{P} \geq 0.1)$, suggesting that the link between diving and isotopes resulted mostly from interindividual differences.

\section{Discussion}

Using a unique long-term deployment of time-depth recorders on ten male little penguins over the whole breeding season and simultaneous stable isotope analyses of blood samples, we described changes in diving behaviour and isotopic composition throughout the breeding season. We were interested at individual level given that most studies extrapolated trip-specific diving and diet data to entire breeding stages. By continuously studying diving and determining isotope composition for individuals over the entire breeding season, we could examine the role of individual variability at different breeding stages and along the breeding season. We found that diving parameters were less variable during guard, with a lower bottom activity index compared to incubation and post-guard, and that depth use index decreased with time. Isotopic composition and diving behaviour showed interindividual differences, suggesting differences in individual strategies, although diving parameters were also highly variable at the individual level.

\section{Changes in foraging behaviour and isotopic composition along the breeding season}

Diving behaviour was less variable during guard than incubation and post-guard. This might be explained by the higher constraints imposed on birds during guard, as they have to return frequently to the colony to feed small chicks and most of the trips are one day long (Chiaradia and Kerry 1999). Such constraints limit their foraging range (Kowalczyk et al. 2015; Sánchez et al. 2018), as shown in other seabird species (Shaffer et al. 2003), which may result in less diverse habitats being available. This, in turn, could also constrain their diving range and prey availability in the vicinity of the colony. Although the foraging location of the equipped little penguins was unknown, this is consistent with GPS data acquired over multiple years and at multiple sites including our study site, which showed that shorter trips performed in guard were associated with coastal foraging areas (Collins et al. 1999; Pelletier et al. 2014; Poupart et al. 2017; Sánchez et al. 2018). In contrast, birds conducted longer and 
more variable trips during incubation and post-guard. In post-guard for instance, little penguins show a bi-modal foraging strategy, with short trips to feed their chicks and longer trips to improve their body condition when it is low (Saraux et al. 2011b). This variability may not be completely measured in our dataset as recordings did not cover the end of the chick-rearing period and only 3 long trips were monitored over 27 trips monitored during post-guard (maximum chick age of 37 days). Such a bimodal strategy is also present during incubation (Kato et al. 2008). However, here most of the days considered in this study corresponded to foraging days during long trips ( $88 \%$ of the dataset during incubation).

Changes in diving behaviour were also observed within breeding stages. During most of the incubation, depth use and bottom activity indices were high and trips were long, as males aimed to replace their body reserves after long fasting and mate guarding and fasting at the start of incubation (as shown in Adélie penguins Pygoscelis adeliae Cottin et al. 2012). Previous research has shown that an increase in trip duration was associated with birds going further away from the colony (Collins et al. 1999). During long trips, birds can probably target more profitable diverse habitats and prey patches that are located further away from the colony than during short trips (Kato et al. 2008). This allows them to increase their body mass over incubation (Chiaradia et al. 2016). However, indices of diving activity and trip durations decreased towards the end of incubation (Chiaradia and Kerry 1999) , a pattern also observed for trip duration in incubating wandering albatross (Salamolard and Weimerskirch 1993; Shaffer et al. 2003) that probably reflect a preparation for the subsequent demanding chick provisioning phase.

Besides differences between guard and the other two stages, a linear decrease in depth use index, as well as a tendency to lower $\delta^{15} \mathrm{~N}$ values, were also observed along the season (with stage or Julian calendar date). This could result from a change in foraging strategy (e.g. different areas targeted or benthic $v s$. pelagic dives) or a change in prey availability, the two alternatives being non-exclusive. Central-place foragers are constrained to forage near the colony and it may create a halo of prey depletion around the colony (Ashmole 1971). Chiaradia et al. (2016) suggested, however, that prey depletion, a horizontally-based concept, may not be applicable for diving birds like penguins that 
explore their environment in the three dimensions. In addition, little penguins, as consumers, have a much smaller total biomass compared to other consumers preying on the same prey in their food web (Chiaradia et al., unpub. data). As such, it is unlikely that little penguin predation alone would deplete its prey. Alternatively, the increase of SST during spring and summer and the associated enhanced stratification of the water column, which lead little penguins to dive shallower and more frequently (Meyer et al. 2020) could further explain the decreasing trend of depth use index along the breeding season.

\section{Interindividual differences in diving behaviour and blood isotopic composition}

We found a high inter-individual variance in isotopic composition and high repeatability, as well as potential differences in individual diving behaviour (although with a lower repeatability). This suggests that individuals may have different foraging strategies, targeting different prey and/or foraging at different locations. Individual diet preferences and repeatability in foraging behaviour is commonly observed in seabirds (Ceia and Ramos 2015; Potier et al. 2015), and has already been observed in little penguins (Ropert-Coudert et al. 2003; Cavallo et al. 2018, 2020). Individual diet preferences are often linked to specialisation in foraging behaviour, targeting the same foraging area (Masello et al. 2013; Patrick et al. 2014) or showing repeatable diving behaviour to feed on one type of prey (Woo et al. 2008; Elliott et al. 2009).

Here, we found higher blood $\delta^{13} \mathrm{C}$ when dives were short and shallow, and both $\delta^{13} \mathrm{C}$ and $\delta^{15} \mathrm{~N}$ increased when bottom activity increased. This may reflect a higher use of shallow coastal areas when dives are short and shallow (Chiaradia et al. 2016; Sánchez et al. 2018). However, we did not observe a significant decrease in $\delta^{13} \mathrm{C}$ along time, as found on a multiple year study (Chiaradia et al. 2016). This may be due to our low sample size but could also result from the stronger inter-individual differences rather than intra-individual (temporal) changes in isotopic values. This suggests that individuals are foraging in different areas with contrasting isotopic landscapes (Graham et al. 2010). There is indeed spatial segregation in little penguins, both between and within colonies (Chiaradia et al. 2012; Pelletier et al. 2014; Sánchez et al. 2018), as well as in other seabird species (e.g. González Solís et al. 2000; Phillips et al. 2004; Wakefield et al. 2013). 
While the small number of individuals did not allow us to investigate quantitatively the potential effect of different diving behaviours on breeding success, some qualitative information was highlighted. Indeed, among the 10 monitored birds, 2 failed relatively early in their reproduction (birds 3095 and 3124), while the other 8 fledged chicks. When comparing their diving behaviour during incubation with that of others, we saw no differences in bottom activity of these two birds. However, they displayed the two highest values of depth use, meaning that these two birds dived deeper and longer, with a smaller proportion of $\mathrm{V}$ dives than other birds. Did these two birds try and exploit a different zone from the others? Were they unable to find prey at lower depths like other birds? The absence of spatial information on the instrumented individual unfortunately precludes us from investigating further the causes for such differences. A greater sample size would be needed to link efficiency in foraging to breeding success.

\section{Intra-individual differences in diving behaviour and blood isotopic composition}

Remarkably, our results also point out that there is a high variability in diving behaviour within individuals over the course of the breeding season. Such intra-individual variability was observed in little penguins breeding at two other colonies in south-eastern Australia (Camprasse et al. 2017). In particular, this variability is likely to be at the core of the bi-modal foraging strategy (short vs. long trips) adopted by little penguins in post guard that target different areas and/or prey during longer trips (Saraux et al. 2011b). This could also translate to plastic response of little penguin facing a highly fluctuating environment (Chilvers 2019). This variability may therefore blur the link with isotopic composition, as the long integration period of the stable isotope measures means that we always look at a combination of short and long trips. Intra-individual variability is not mutually exclusive with individual specialisation, as they may occur at different timescales. One individual can, for example, display a specific foraging behaviour over a short period of time and shift to another, which seemed to be the case for some of our individuals between stages (e.g. 3024 and 3089), while other individuals showed greater variability even within a stage (e.g. 3013). The design of future bio-logging studies should thus consider within-individual variability to ensure sampling is representative of the entire breeding stage. 


\section{Conclusions}

In seabirds, foraging behaviour is strongly shaped by the constraints of being a central place forager. This behaviour certainly evolved in a context where prey resources are predictable, and peak when demand is higher for parents (Schreiber and Burger 2001). In the face of global change, this predictability of food resources is reduced, hence making it more challenging for meso- and toppredators to adapt to a changing environment (Edwards and Richardson 2004; Durant et al. 2007). Long-term monitoring of the ecology of top predators is a precious tool to measure the effects of changing ecosystems (Bost et al. 2009). Our study indicates that in order to compare foraging data between and within years it is important to record the activity of individuals in each breeding stage, as well as to consider the timing of deployment in the analyses as the foraging activity changed between and within stages. The high variability in diving and isotopic composition found in our study suggests that little penguins have a flexible foraging behaviour, which could be advantageous for future survival in the ongoing environmental changes.

\section{Acknowledgements}

We would like to thank the research staff and rangers at the Phillip Island Nature Park for their help. Finally, we thank three anonymous reviewers for their valuable comments. This is a post-peer-review, pre-copyedit version of an article published in Marine Biology. The final authenticated version is available online at: http://dx.doi.org/10.1007/s00227-021-03867-2

\section{Declarations}

\section{Funding}

The study was financially supported by the Japan Science Society, the Australian Academy of Science, the University of Strasbourg, the Penguin Foundation and the Japan Society for the Promotion of Science.

\section{Conflict of interest}

No conflict of interest to declare. 


\section{Ethics approval}

The study was conducted with research permits issued by the Department of Environment, Land, Water and Planning, Victorian State Government, Australia, and ethics approvals from the Animal Ethics Committee of Phillip Island Nature Parks.

\section{Data availability}

Data are available upon request to Dr Andre Chiaradia achiaradia@penguins.org.au

\section{Author's contribution}

YRC, AK, AC designed the study, IZ, AC performed the field work, $\mathrm{KH}$ performed the isotope analyses, AK and YRC ran logger data analyses, FA, CS analysed the data, FA, CS, AC wrote the manuscript. All authors read and commented on the final manuscript.

\section{References}

Alonso H, Granadeiro JP, Paiva VH, Dias AS, Ramos JA, Catry P (2012) Parent-offspring dietary segregation of Cory's shearwaters breeding in contrasting environments. Mar Biol 159:1197-1207.https://doi.org/10.1007/s00227-012-1900-2

Arnould JP, Dann P, Cullen JM (2004) Determining the sex of little penguins (Eudyptula minor) in northern Bass Strait using morphometric measurements. Emu 104:261-265. https://doi.org/10.1071/MU04035

Ashmole NP (1971) Seabird ecology and the marine environment. Avian Biol 1:223-286.

Bannasch R, Wilson RP, Culik B (1994) Hydrodynamic aspects of design and attachment of a back-mounted device in Penguins. J Exp Biol 194:83-96

Bearhop S, Teece MA, Waldron S, Furness RW (2000) Influence of lipid and uric acid on $\delta^{13} \mathrm{C}$ and $\delta^{15} \mathrm{~N}$ values of avian blood: implications for trophic studies. The Auk 117:504-507. https://doi.org/10.1093/auk/117.2.504

Bearhop S, Waldron S, Votier SC, Furness RW (2002) Factors that influence assimilation rates and fractionation of nitrogen and carbon stable isotopes in avian blood and feathers. Physiol Biochem Zool 75:451-458. https://doi.org/10.1086/342800

Bell WJ (1991) Searching behaviour: the behavioural ecology of finding resources. Chapman and Hall, London

Bertram DF, Welham CVJ, Ydenberg RC (1996) Flexible effort in breeding seabirds: adjustment of provisioning according to nestling age and mass. Can J Zool 74:18761881. https://doi.org/10.1139/z96-211 
Bost C-A, Cotté C, Bailleul F, Cherel Y, Charrassin J-B, Guinet C, Ainley DG, Weimerskirch $\mathrm{H}$ (2009) The importance of oceanographic fronts to marine birds and mammals of the southern oceans. J Mar Syst 78:363-376.

https://doi.org/10.1016/j.jmarsys.2008.11.022

Camprasse ECM, Sutton GJ, Berlincourt M, Arnould JPY (2017) Changing with the times: little penguins exhibit flexibility in foraging behaviour and low behavioural consistency. Mar Biol 164:169. https://doi.org/10.1007/s00227-017-3193-y

Cannell BL, Cullen JM (1998) The foraging behaviour of little penguins Eudyptula minor at different light levels. Ibis 140:467-471. https://doi.org/10.1111/j.1474919X.1998.tb04608.x

Carleton SA, Del Rio CM (2005) The effect of cold-induced increased metabolic rate on the rate of ${ }^{13} \mathrm{C}$ and ${ }^{15} \mathrm{~N}$ incorporation in house sparrows (Passer domesticus). Oecologia 144:226-232. https://doi.org/10.1007/s00442-005-0066-8

Cavallo C, Chiaradia A, Deagle BE, McInnes JC, Sánchez S, Hays GC, Reina RD (2018) Molecular analysis of predator scats reveals role of salps in temperate inshore food webs. Front Mar Sci 5:381. https://doi.org/10.3389/fmars.2018.00381

Cavallo C, Chiaradia A, Deagle BE, Hays GC, Jarman S, McInnes JC, Ropert-Coudert Y, Sánchez S, Reina RD (2020) Quantifying prey availability using the foraging plasticity of a marine predator, the little penguin. Funct Ecol. https://doi.org/10.1111/1365-2435.13605

Ceia FR, Ramos JA (2015) Individual specialization in the foraging and feeding strategies of seabirds: a review. Mar Biol 162:1923-1938. https://doi.org/10.1007/s00227-0152735-4

Chaurand T, Weimerskirch H (1994) The regular alternation of short and long foraging trips in the blue petrel Halobaena caerulea: a previously undescribed strategy of food provisioning in a pelagic seabird. J Anim Ecol 63:275-282. https://doi.org/10.2307/5546

Chiaradia A, Nisbet IC (2006) Plasticity in parental provisioning and chick growth in little penguins Eudyptula minor in years of high and low breeding success. Ardea 94:257270

Chiaradia A, Ropert-Coudert Y, Kato A, Mattern T, Yorke J (2007) Diving behaviour of little penguins from four colonies across their whole distribution range: bathymetry affecting diving effort and fledging success. Mar Biol 151:1535-1542. https://doi.org/10.1007/s00227-006-0593-9

Chiaradia A, Forero MG, Hobson KA, Cullen JM (2010) Changes in diet and trophic position of a top predator 10 years after a mass mortality of a key prey. ICES J Mar Sci J Cons 67:1710-1720. https://doi.org/10.1093/icesjms/fsq067

Chiaradia A, Forero MG, Hobson KA, Swearer SE, Hume F, Renwick L, Dann P (2012) Diet segregation between two colonies of little penguins Eudyptula minor in southeast Australia. Austral Ecol 37:610-619. https://doi.org/10.1111/j.1442-9993.2011.02323.x 
Chiaradia A, Ramírez F, Forero MG, Hobson KA (2016) Stable Isotopes $\left(\delta^{13} \mathrm{C}, \delta^{15} \mathrm{~N}\right)$ combined with conventional dietary approaches reveal plasticity in central-place foraging behavior of little penguins Eudyptula minor. Front Ecol Evol 3:154. https://doi.org/10.3389/fevo.2015.00154

Chiaradia AF, Kerry KR (1999) Daily nest attendance and breeding performance in the little penguin Eudyptula minor at Phillip Island, Australia. Mar Ornithol 27:13-20

Chilvers BL (2019) Variability of little blue penguin (Eudyptula minor) diving behaviour across New Zealand. N Z J Ecol 43:1-8

Collins M, Cullen JM, Dann P (1999) Seasonal and annual foraging movements of little penguins from Phillip Island, Victoria. Wildl Res 26:705-721. https://doi.org/10.1071/wr98003

Cottin M, Raymond B, Kato A, Amélineau F, Le Maho Y, Raclot T, Galton-Fenzi B, Meijers A, Ropert-Coudert Y (2012) Foraging strategies of male Adélie penguins during their first incubation trip in relation to environmental conditions. Mar Biol 159:1843-1852. https://doi.org/10.1007/s00227-012-1974-X

Davoren GK, Burger AE (1999) Differences in prey selection and behaviour during selffeeding and chick provisioning in rhinoceros auklets. Anim Behav 58:853-863. https://doi.org/10.1006/anbe.1999.1209

Durant JM, Hjermann DØ, Ottersen G, Stenseth NC (2007) Climate and the match or mismatch between predator requirements and resource availability. Clim Res 33:271283. https://doi.org/10.3354/cr033271

Edwards M, Richardson AJ (2004) Impact of climate change on marine pelagic phenology and trophic mismatch. Nature 430:881-884. https://doi.org/10.1038/nature02808

Elliott KH, Woo KJ, Gaston AJ (2009) Specialization in Murres: the story of eight specialists. Waterbirds 32:491-506. https://doi.org/10.1675/063.032.0402

Erikstad KE, Asheim M, Fauchald P, Dahlhaug L, Tveraa T, Dahlhaug P (1997) Adjustment of parental effort in the puffin; the roles of adult body condition and chick size. Behav Ecol Sociobiol 40:95-100. https://doi.org/10.1007/s002650050320

Fasola M, Saino N (1995) Sex-biased parental-care allocation in three tern species (Laridae, Aves). Can J Zool 73:1461-1467. https://doi.org/10.1139/z95-172

Fry B (2006) Stable isotope ecology. Springer, New York

González-Solís J, Croxall JP, Wood AG (2000) Sexual dimorphism and sexual segregation in foraging strategies of northern giant petrels, Macronectes halli, during incubation. Oikos 90:390-398. https://doi.org/10.1034/j.1600-0706.2000.900220.x

Graham BS, Koch PL, Newsome SD, McMahon KW, Aurioles D (2010) Using isoscapes to trace the movements and foraging behavior of top predators in oceanic ecosystems. In: West JB, Bowen GJ, Dawson TE, Tu KP (eds) Isoscapes: Understanding movement, pattern, and process on Earth through isotope mapping. Springer Netherlands, Dordrecht, pp 299-318 
Hobson KA, Welch HE (1992) Determination of trophic relationships within a high Arctic marine food web using $\delta^{13} \mathrm{C}$ and $\delta^{15} \mathrm{~N}$ analysis. Mar Ecol Prog Ser 9-18

Jackson AL, Inger R, Parnell AC, Bearhop S (2011) Comparing isotopic niche widths among and within communities: SIBER - Stable Isotope Bayesian Ellipses in R. J Anim Ecol 80:595-602. https://doi.org/10.1111/j.1365-2656.2011.01806.x

Kato A, Ropert-Coudert Y, Grémillet D, Cannell B (2006) Locomotion and foraging strategy in foot-propelled and wing-propelled shallow-diving seabirds. Mar Ecol Prog Ser 308:293-301. https://doi.org/10.3354/meps308293

Kato A, Ropert-Coudert Y, Chiaradia A (2008) Regulation of trip duration by an inshore forager, the little penguin (Eudyptula minor), during incubation. The Auk 125:588593. https://doi.org/10.1525/auk.2008.06273

Kerry K, Clarke J, Else G (1993) The use of an automated weighing and recording system for the study of the biology of adelie penguins (Pygoscelis adeliae). Proc NIPR Symp Polar Biol 6:62-75

Kowalczyk ND, Reina RD, Preston TJ, Chiaradia A (2015) Environmental variability drives shifts in the foraging behaviour and reproductive success of an inshore seabird. Oecologia 178:967-979. https://doi.org/10.1007/s00442-015-3294-6

Lack DL (1968) Ecological Adaptations for Breeding in Birds. Methuen, North Yorkshire

Le Guen C, Kato A, Raymond B, Barbraud C, Beaulieu M, Bost C-A, Delord K, MacIntosh AJ, Meyer X, Raclot T (2018) Reproductive performance and diving behaviour share a common sea-ice concentration optimum in Adélie penguins (Pygoscelis adeliae). Glob Change Biol 24:5304-5317. https://doi.org/10.1111/gcb.14377

Martin TE (1987) Food as a limit on breeding birds: a life-history perspective. Annu Rev Ecol Syst 18:453-487. https://doi.org/10.1146/annurev.es.18.110187.002321

Masello JF, Wikelski M, Voigt CC, Quillfeldt P (2013) Distribution patterns predict individual specialization in the diet of dolphin gulls. PLoS ONE. https://doi.org/10.1371/journal.pone.0067714

Meyer X, MacIntosh AJJ, Chiaradia A, Kato A, Ramírez F, Sueur C, Ropert-Coudert Y (2020) Oceanic thermal structure mediates dive sequences in a foraging seabird. Ecol Evol 10:6610-6622. https://doi.org/10.1002/ece3.6393

Nakagawa S, Schielzeth H (2010) Repeatability for Gaussian and non-Gaussian data: a practical guide for biologists. Biol Rev 85:935-956. https://doi.org/10.1111/j.1469185X.2010.00141.x

Patrick SC, Bearhop S, Grémillet D, Lescroël A, Grecian WJ, Bodey TW, Hamer KC, Wakefield E, Le Nuz M, Votier SC (2014) Individual differences in searching behaviour and spatial foraging consistency in a central place marine predator. Oikos 123:33-40. https://doi.org/10.1111/j.1600-0706.2013.00406.x 
Pelletier L, Chiaradia A, Kato A, Ropert-Coudert Y (2014) Fine-scale spatial age segregation in the limited foraging area of an inshore seabird species, the little penguin. Oecologia 176:399-408. https://doi.org/10.1007/s00442-014-3018-3

Phillips RA, Silk JRD, Phalan B, Catry P, Croxall JP (2004) Seasonal sexual segregation in two Thalassarche albatross species: competitive exclusion, reproductive role specialization or foraging niche divergence? Proc R Soc Lond B Biol Sci 271:12831291. https://doi.org/10.1098/rspb.2004.2718

Piersma T, Drent J (2003) Phenotypic flexibility and the evolution of organismal design. Trends Ecol Evol 18:228-233. https://doi.org/10.1016/S0169-5347(03)00036-3

Post DM, Layman CA, Arrington DA, Takimoto G, Quattrochi J, Montana CG (2007) Getting to the fat of the matter: models, methods and assumptions for dealing with lipids in stable isotope analyses. Oecologia 152:179-189. https://doi.org/10.1007/s00442-0060630-x

Potier S, Carpentier A, Grémillet D, Leroy B, Lescroël A (2015) Individual repeatability of foraging behaviour in a marine predator, the great cormorant, Phalacrocorax carbo. Anim Behav 103:83-90. https://doi.org/10.1016/j.anbehav.2015.02.008

Poupart TA, Waugh SM, Bost C, Bost C-A, Dennis T, Lane R, Rogers K, Sugishita J, Taylor GA, Wilson K-J, Zhang J, Arnould JPY (2017) Variability in the foraging range of Eudyptula minor across breeding sites in central New Zealand. N Z J Zool 44:225244. https://doi.org/10.1080/03014223.2017.1302970

R Core Team (2017) A language and environment for statistical computing. Vienna, Austria: R Foundation for Statistical Computing; 2017

Robinson S, Chiaradia A, Hindell MA (2005) The effect of body condition on the timing and success of breeding in little penguins Eudyptula minor. Ibis 147:483-489. https://doi.org/10.1111/j.1474-919x.2005.00431.x

Ropert-Coudert Y, Kato A, Naito Y, Cannell BL (2003) Individual diving strategies in the little penguin. Waterbirds 26:403-408. https://doi.org/10.1675/15244695(2003)026[0403:IDSITL]2.0.CO;2

Ropert-Coudert Y, Wilson RP, Daunt F, Kato A (2004) Patterns of energy acquisition by a central place forager: benefits of alternating short and long foraging trips. Behav Ecol 15:824-830. https://doi.org/10.1093/beheco/arh086

Ropert-Coudert Y, Kato A, Wilson RP, Cannell B (2006) Foraging strategies and prey encounter rate of free-ranging little penguins. Mar Biol 149:139-148. https://doi.org/10.1007/s00227-005-0188-X

Ropert-Coudert Y, Knott N, Chiaradia A, Kato A (2007) How do different data logger sizes and attachment positions affect the diving behaviour of little penguins? Deep Sea Res Part II Top Stud Oceanogr 54:415-423. https://doi.org/10.1016/j.dsr2.2006.11.018

Ropert-Coudert Y, Kato A, Grémillet D, Crenner F (2012) Bio-logging: recording the ecophysiology and behaviour of animals moving freely in their environment. In: Le 
Galliard J-F, Guarini J-M, Gaill F (eds) Sensors for ecology: towards integrated knowledge of ecosystems. CNRS, Paris, pp 17-41

Salamolard M, Weimerskirch H (1993) Relationship between foraging effort and energy requirement throughout the breeding season in the wandering albatross. Funct Ecol 643-652. https://doi.org/10.2307/2390184

Sánchez S, Reina R, Kato A, Ropert-Coudert Y, Cavallo C, Hays G, Chiaradia A (2018) Within-colony spatial segregation leads to foraging behaviour variation in a seabird. Mar Ecol Prog Ser 606:215-230. https://doi.org/10.3354/meps12764

Saraux C, Chiaradia A, Le Maho Y, Ropert-Coudert Y (2011a) Everybody needs somebody: unequal parental effort in little penguins. Behav Ecol 22:837-845. https://doi.org/10.1093/beheco/arr049

Saraux C, Robinson-Laverick SM, Le Maho Y, Ropert-Coudert Y, Chiaradia A (2011b) Plasticity in foraging strategies of inshore birds: how little penguins maintain body reserves while feeding offspring. Ecology 92:1909-1916. https://doi.org/10.1890/110407.1

Schreiber EA, Burger J (2001) Biology of marine birds. CRC Press, Boca Raton

Shaffer SA, Costa DP, Weimerskirch H (2003) Foraging effort in relation to the constraints of reproduction in free-ranging albatrosses. Funct Ecol 17:66-74. https://doi.org/10.1046/j.1365-2435.2003.00705.x

Stearns SC (1992) The Evolution of Life Histories. Oxford University Press, Oxford

Sutherland DR, Dann P (2012) Improving the accuracy of population size estimates for burrow-nesting seabirds. Ibis 154:488-498. https://doi.org/10.1111/j.1474919X.2012.01234.x

Takahashi A, Watanuki Y, Sato K, Kato A, Arai N, Nishikawa J, Naito Y (2003) Parental foraging effort and offspring growth in Adélie penguins: does working hard improve reproductive success? Funct Ecol 17:590-597. https://doi.org/10.1046/j.13652435.2003.00772.x

Wakefield ED, Bodey TW, Bearhop S, Blackburn J, Colhoun K, Davies R, Dwyer RG, Green J, Grémillet D, Jackson AL, Jessopp MJ, Kane A, Langston RHW, Lescroël A, Murray S, Nuz ML, Patrick SC, Péron C, Soanes L, Wanless S, Votier SC, Hamer KC (2013) Space partitioning without territoriality in Gannets. Science. https://doi.org/10.1126/science.1236077

Weimerskirch H, Cherel Y, Cuenot-Chaillet F, Ridoux V (1997) Alternative foraging strategies and resource allocation by male and female wandering albatrosses. Ecology 78:2051-2063. https://doi.org/10.1890/0012-9658(1997)078[2051:AFSARA]2.0.CO;2

Wilson LJ, Daunt F, Wanless S (2004) Self-feeding and chick provisioning diet differ in the common guillemot Uria aalge. Ardea 92:197-207

Wilson R (1995) Foraging ecology. In: The penguins Spheniscidae. Oxford University Press, Oxford, pp 81-106 
Wilson RP (2003) Penguins predict their performance. Mar Ecol Prog Ser 249:305-310. https://doi.org/10.3354/meps249305

Wilson RP, Wilson M-PT (1990) Foraging ecology of breeding Spheniscus penguins. In: Davis LS, Darby J (eds) Penguin biology. Academic Press, San Diego, pp 181-206

Wilson RP, Pütz K, Peters G, Culik B, Scolaro JA, Charrassin J-B, Ropert-Coudert Y (1997) Long-term attachment of transmitting and recording devices to penguins and other seabirds. Wildl Soc Bull 25:101-106

Woo KJ, Elliott KH, Davidson M, Gaston AJ, Davoren GK (2008) Individual specialization in diet by a generalist marine predator reflects specialization in foraging behaviour. $\mathrm{J}$ Anim Ecol 77:1082-1091. https://doi.org/10.1111/j.1365-2656.2008.01429.x

Ydenberg RC, Clark CW (1989) Aerobiosis and anaerobiosis during diving by western grebes: an optimal foraging approach. J Theor Biol 139:437-447. https://doi.org/10.1016/S0022-5193(89)80064-5

Zimmer I, Wilson RP, Beaulieu M, Ropert-Coudert Y, Kato A, Ancel A, Plötz J (2010) Dive efficiency versus depth in foraging emperor penguins. Aquat Biol 8:269-277. https://doi.org/10.3354/ab00213

Zuur A, Ieno EN, Smith GM (2007) Analyzing ecological data. Springer, New York 
Table 1 Summary of the post-hoc tests comparing PC1 among breeding stages after linear models. One model per individual was conducted. Results were then compared to the general trend observed in all 10 individuals: Yes means the result is the same as in the general linear mixed model, No means no effect was found when one was expected or an effect was found when none was expected, while opposite means that an opposite effect was found. I stands for Incubation, G for Guard and PG for Post-Guard.

\begin{tabular}{|c|c|c|c|c|}
\hline ID & $\begin{array}{l}\text { Breeding stages } \\
\text { compared }\end{array}$ & Estimates $\pm \mathrm{SE}$ & P-values & $\begin{array}{l}\text { Coherent with } \\
\text { global pattern }\end{array}$ \\
\hline \multirow{3}{*}{3024} & G-I & $0.72 \pm 0.53$ & 0.380 & Yes \\
\hline & PG-I & $-1.64 \pm 0.51$ & 0.010 & Yes \\
\hline & PG-G & $-2.36 \pm 0.57$ & 0.001 & Yes \\
\hline \multirow{3}{*}{3053} & G-I & $-1.47 \pm 0.52$ & 0.023 & No \\
\hline & PG-I & $-0.85 \pm 0.70$ & 0.449 & No \\
\hline & PG-G & $0.61 \pm 0.73$ & 0.678 & No \\
\hline \multirow{3}{*}{3072} & G-I & $-2.17 \pm 0.64$ & 0.006 & No \\
\hline & PG-I & $-0.70 \pm 0.60$ & 0.482 & No \\
\hline & PG-G & $1.46 \pm 0.68$ & 0.097 & No \\
\hline \multirow{3}{*}{3089} & G-I & $-1.05 \pm 0.55$ & 0.155 & Yes \\
\hline & PG-I & $-4.66 \pm 0.48$ & $<0.001$ & Yes \\
\hline & PG-G & $-3.61 \pm 0.51$ & $<0.001$ & Yes \\
\hline 3118 & G-I & $0.16 \pm 0.73$ & 0.825 & Yes \\
\hline 4026 & PG-I & $1.55 \pm 0.47$ & 0.003 & Opposite \\
\hline A18 & G-I & $0.28 \pm 0.74$ & 0.708 & Yes \\
\hline
\end{tabular}


Table 2. Summary of the post-hoc tests comparing PC2 among breeding stages after linear models.

One model per individual was conducted. Results were then compared to the general trend observed in all 10 individuals: Yes means the result is the same as in the general linear mixed model, $\sim$ means a similar trend was detected though not quite significant (i.e. $0.05<\mathrm{P}<0.10$ ). No means no effect was found when one was expected or an effect was found when none was expected. I stands for Incubation, G for Guard and PG for Post-Guard.

\begin{tabular}{|c|c|c|c|c|}
\hline ID & $\begin{array}{l}\text { Breeding stages } \\
\text { compared }\end{array}$ & Estimates $\pm \mathrm{SE}$ & P-values & $\begin{array}{l}\text { Coherent with } \\
\text { global pattern }\end{array}$ \\
\hline \multirow{3}{*}{3024} & G-I & $1.25 \pm 0.55$ & 0.080 & No \\
\hline & PG-I & $2.30 \pm 0.53$ & $<0.001$ & No \\
\hline & PG-G & $1.05 \pm 0.59$ & 0.193 & No \\
\hline \multirow{3}{*}{3053} & G-I & $-1.69 \pm 0.46$ & 0.003 & Yes \\
\hline & PG-I & $-0.27 \pm 0.62$ & 0.901 & Yes \\
\hline & PG-G & $1.42 \pm 0.64$ & 0.082 & $\sim$ \\
\hline \multirow{3}{*}{3072} & G-I & $-1.77 \pm 0.74$ & 0.058 & $\sim$ \\
\hline & PG-I & $-0.77 \pm 0.69$ & 0.514 & Yes \\
\hline & PG-G & $1.00 \pm 0.78$ & 0.412 & No \\
\hline \multirow{3}{*}{3089} & G-I & $-2.14 \pm 0.71$ & 0.012 & Yes \\
\hline & PG-I & $1.19 \pm 0.61$ & 0.137 & Yes \\
\hline & PG-G & $3.34 \pm 0.65$ & $<0.001$ & Yes \\
\hline 3118 & G-I & $-1.33 \pm 0.60$ & 0.043 & Yes \\
\hline 4026 & PG-I & $-0.87 \pm 1.05$ & 0.414 & Yes \\
\hline A18 & G-I & $-1.13 \pm 0.48$ & 0.025 & Yes \\
\hline
\end{tabular}




\section{Figure legends}

Figure 1 Variable plot of the Principal Component Analysis run over all daily diving parameters. The plot displays the projection of each variable in the first 2 component plane. The color of the variable indicates its contribution to the first two axes.

Figure 2 Daily diving parameters projected in the first 2 axes of the PCA plane. Points are coloured by A) breeding stage, B) Chick age (relative to hatching date negative value representing eggs, binned in 10 day period), and C) Julian calendar dates (binned in 10 day period). Minimum convex polygons per categories (either breeding stage or 10 day periods) are represented and the large circles represent the barycenter of the individuals for each category.

Figure $3 \mathrm{PC} 1$ (on the left) and PC2 (on the right) according to breeding stages (A \& D), chick age (relative to hatching date B and E), and Julian calendar date (C and F). Chick age and Julian calendar date were binned in 10 day periods. The numbers of daily values per category are written at the bottom of each panel. Panels B, C, E and F present means \pm SE. Categories with less than 10 daily values are not represented here.

Figure 4 Daily diving parameters projected in the first 2 axes of the PCA plane. Points are coloured by individual. Minimum convex polygons per individual are represented and the large circles represent the barycenter of the individuals for each category.

Figure 5 Daily diving parameters projected in the first 2 axes of the PCA plane according to breeding stage and individual. Each panel represents an individual and points are coloured by breeding stage. Minimum convex polygons per breeding stage are represented and the large circles represent the 
barycenter of the individuals for each stage. A common scale to each panel has been used to show the difference in variability between individuals.

Figure 6 Stable isotopic values in whole blood $\left(\delta^{15} \mathrm{~N}\right.$ and $\delta^{13} \mathrm{C}$ values in \%o). Points are coloured by individual. Shaded areas indicate the minimum convex polygon per individual.

Figure 7 Stable isotope values in whole blood according to chick age (on the left) and Julian calendar date (on the right). Means $\pm \mathrm{SE} \delta^{15} \mathrm{~N}$ are presented on the bottom panels and $\delta^{13} \mathrm{C}$ values on the top panels. Chick age and Julian calendar date were binned in 10 day periods. The numbers of samples per category are written at the bottom of each panel. Categories with less than 3 samples are not represented here. Note that the chick age and Julian calendar date correspond to the moment blood was sampled but the isotopic values represent the diet and physiology of the penguins in the previous 4 weeks.

Figure 8 Stable isotope values in whole blood according to diving patterns. $\delta^{15} \mathrm{~N}$ are presented on the bottom panels and $\delta^{13} \mathrm{C}$ values on the top panels according to PC1 (on the left) and PC2 (on the right). Because isotopic values in whole blood represent the diet and physiology of the penguins in the previous 4 weeks, $\mathrm{PC} 1$ and $\mathrm{PC} 2$ values are the average of daily $\mathrm{PC} 1$ (PC2) values over the 28 days previous to blood sample. The solid line indicates a significant relationship between $\delta^{13} \mathrm{C}$ values and $\mathrm{PC} 1$, while dashed lines represent trends $(\mathrm{P}=0.06$ and 0.07). n.s. stands for not significant. 




Figure 1 


\section{PCA on daily diving parameters}

\section{A) Breeding stages}

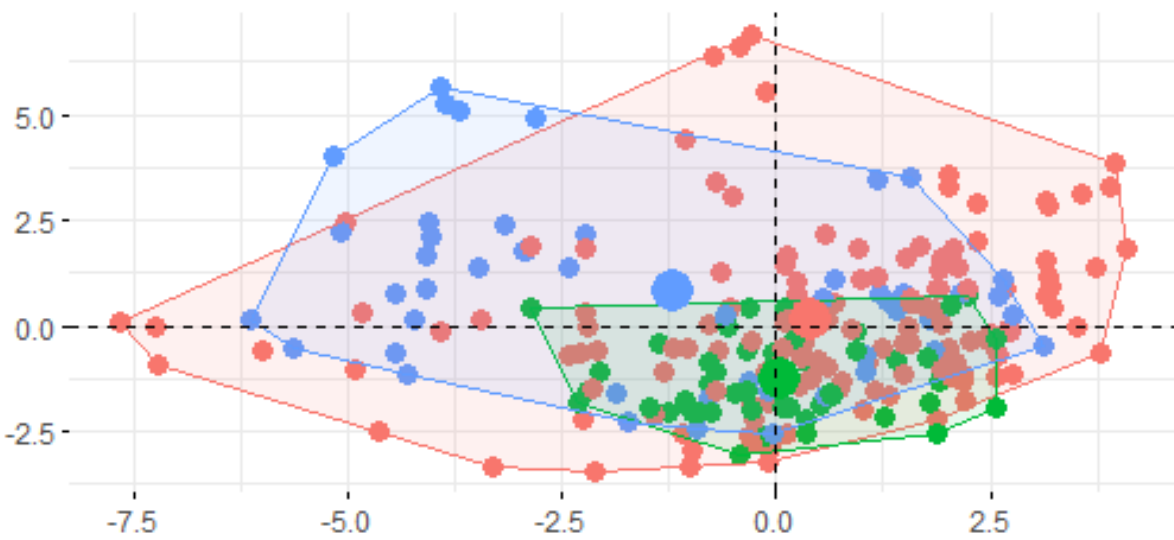

Breeding stage

1-Incub

2-Guard

3-Post-Guard

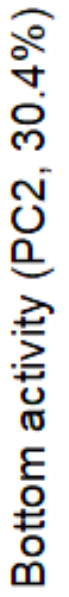

B) Chick age

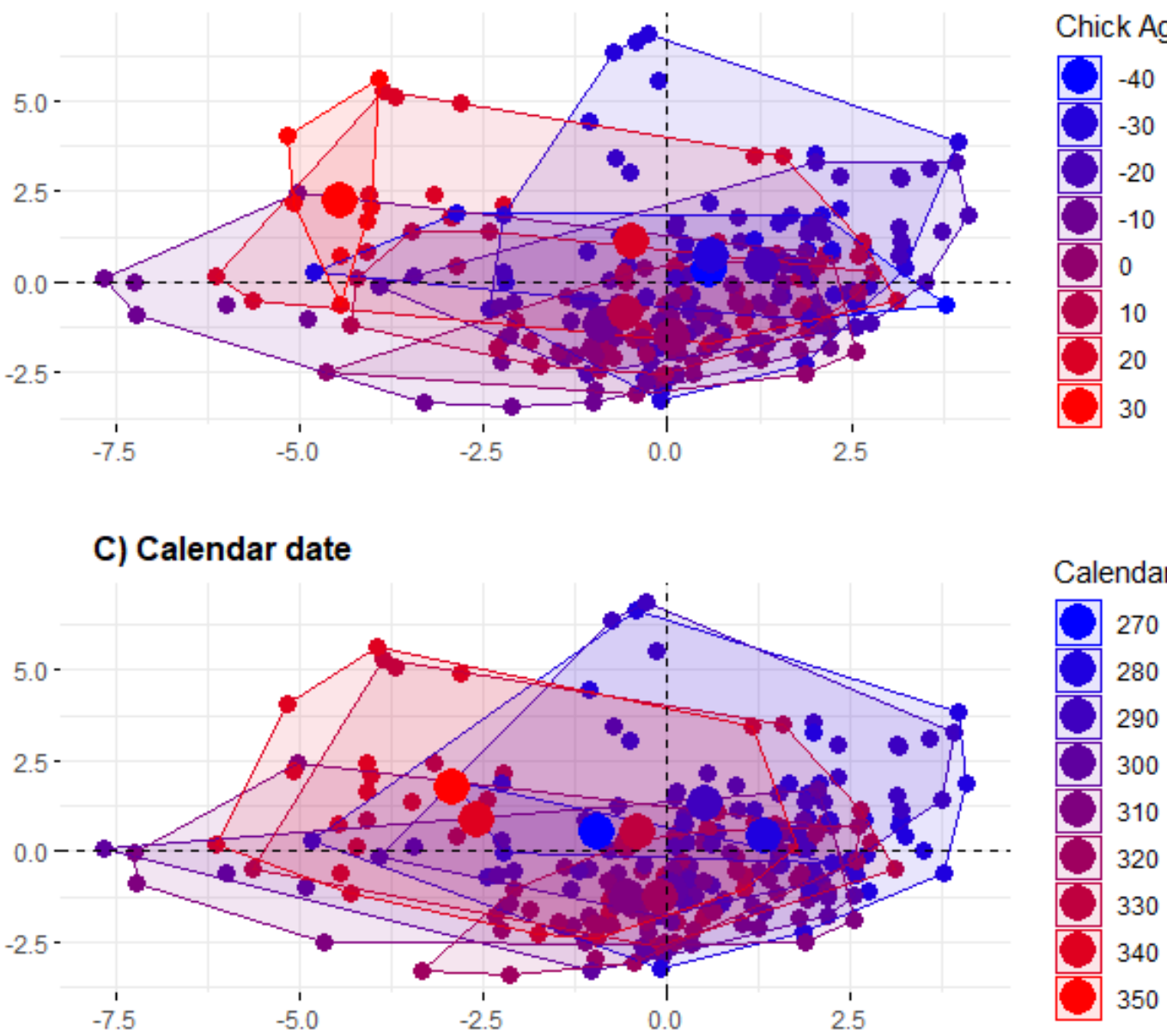

Depth use (PC1, $44.5 \%$ )

Figure 2 
Depth use (PC1)

A) Breeding stages

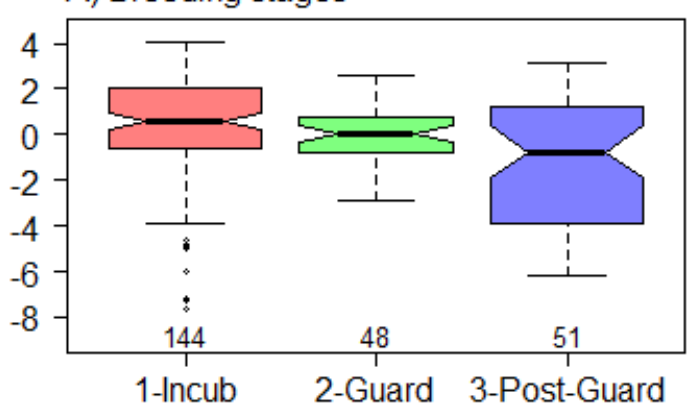

B) Chick age

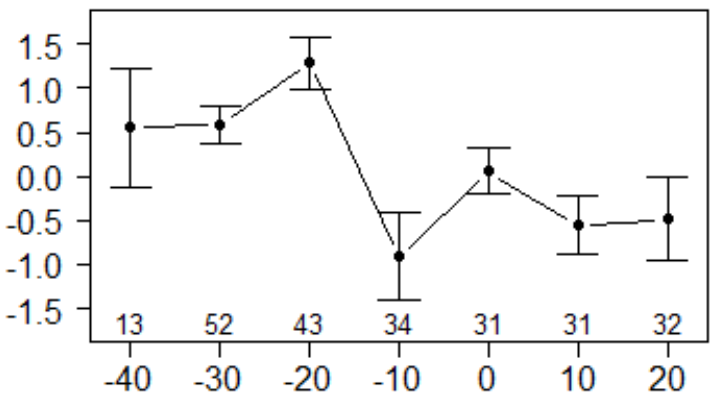

C) Calendar date

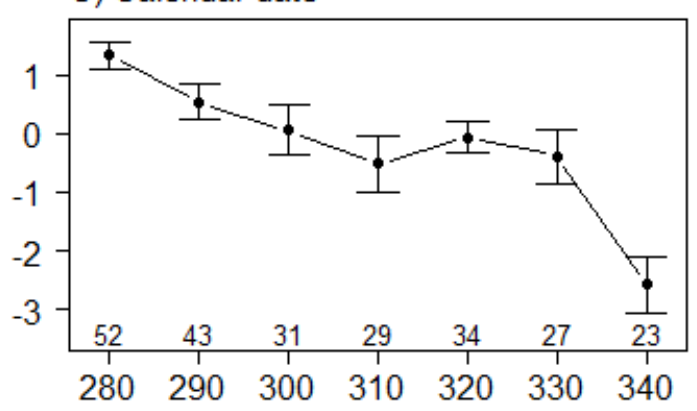

Bottom activity (PC2)

D) Breeding stages

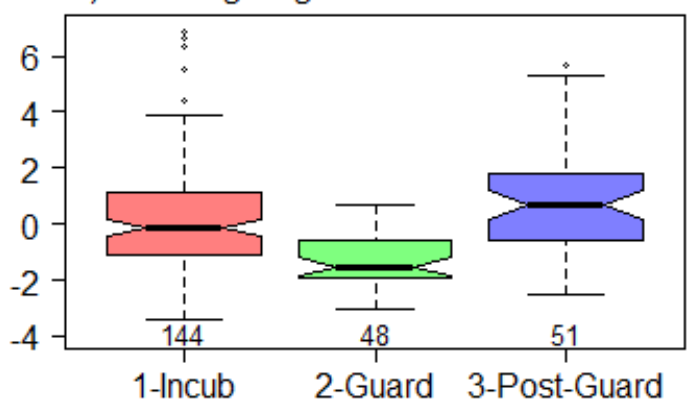

E) Chick age



F) Calendar date

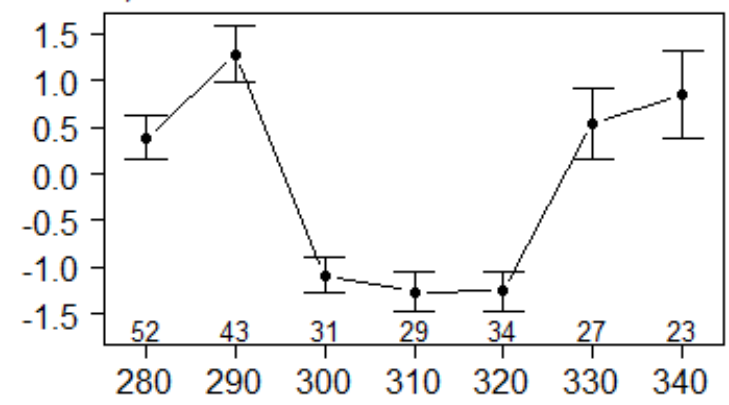

Figure 3 


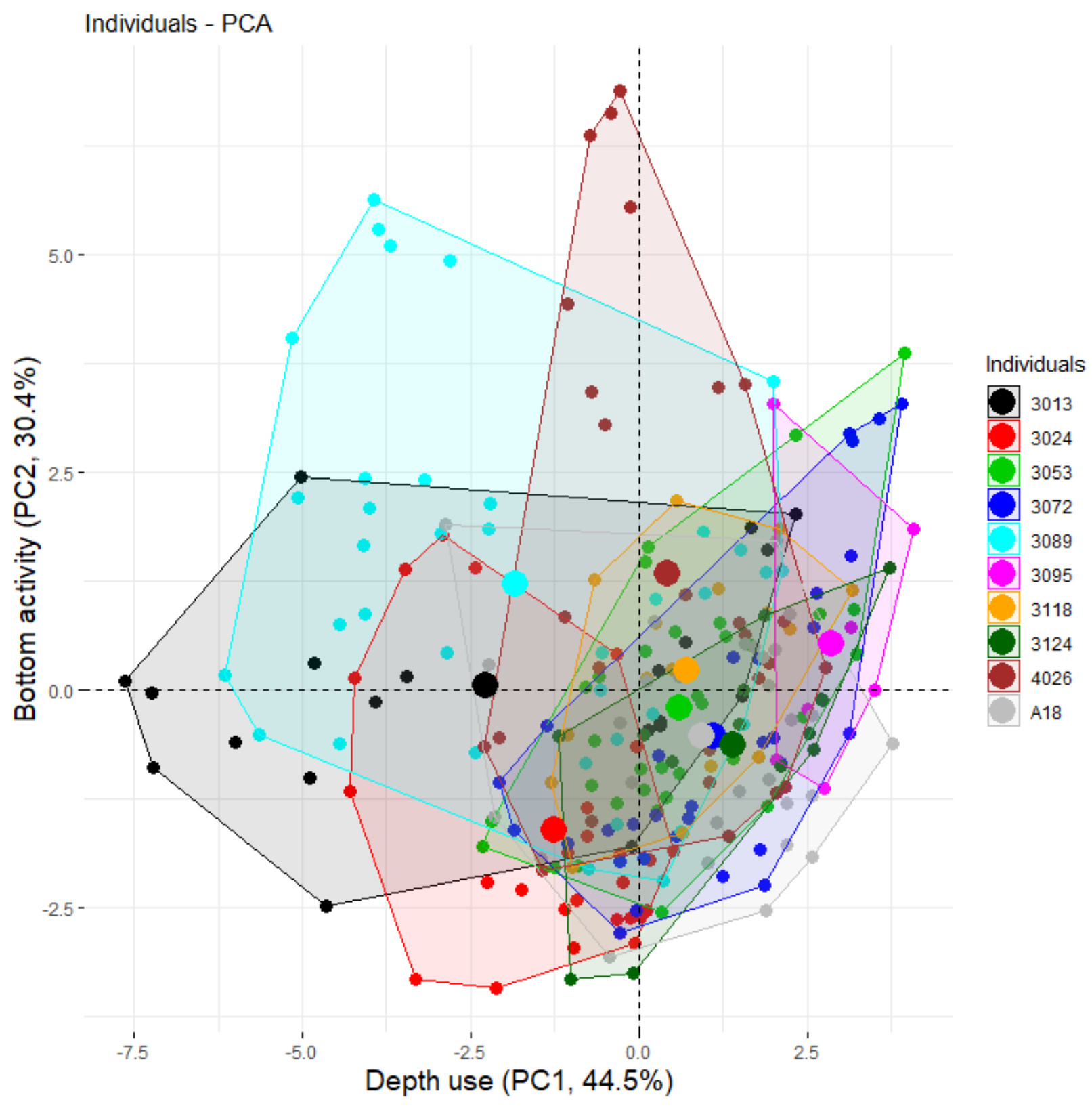

Figure 4 
PCA on daily diving parameters
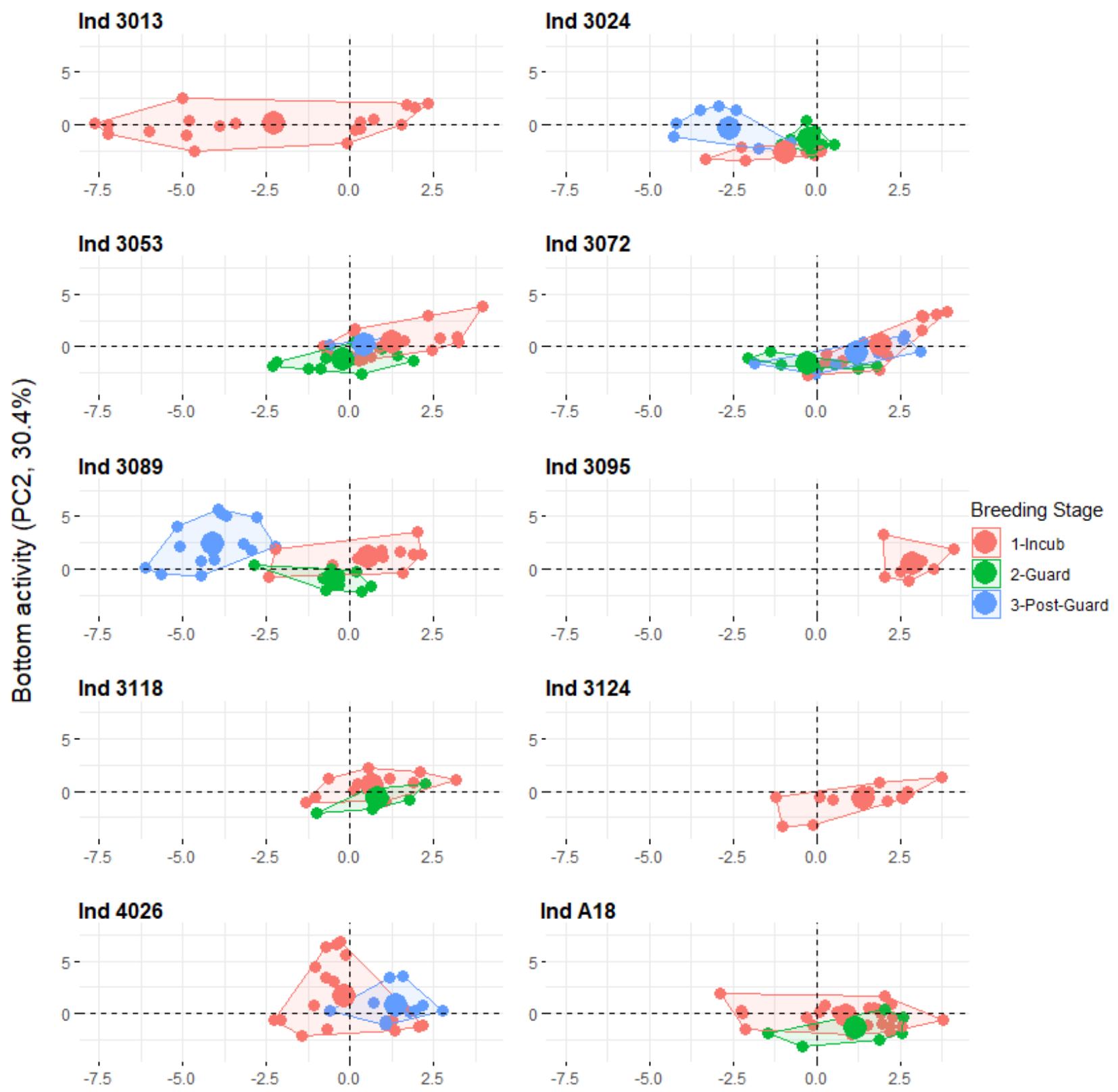

Depth use (PC1, $44.5 \%)$

\section{Figure 5}




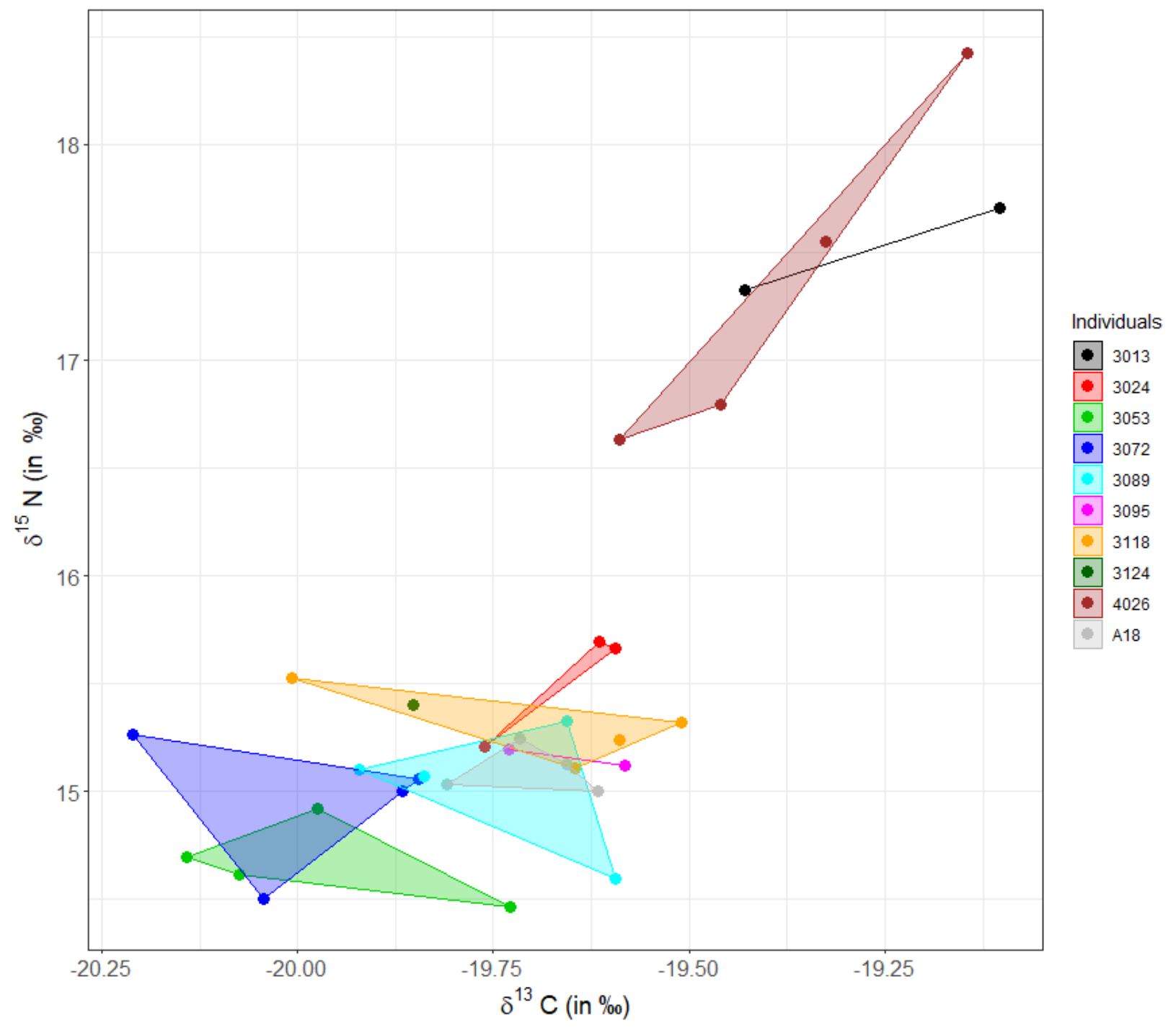

Figure 6 

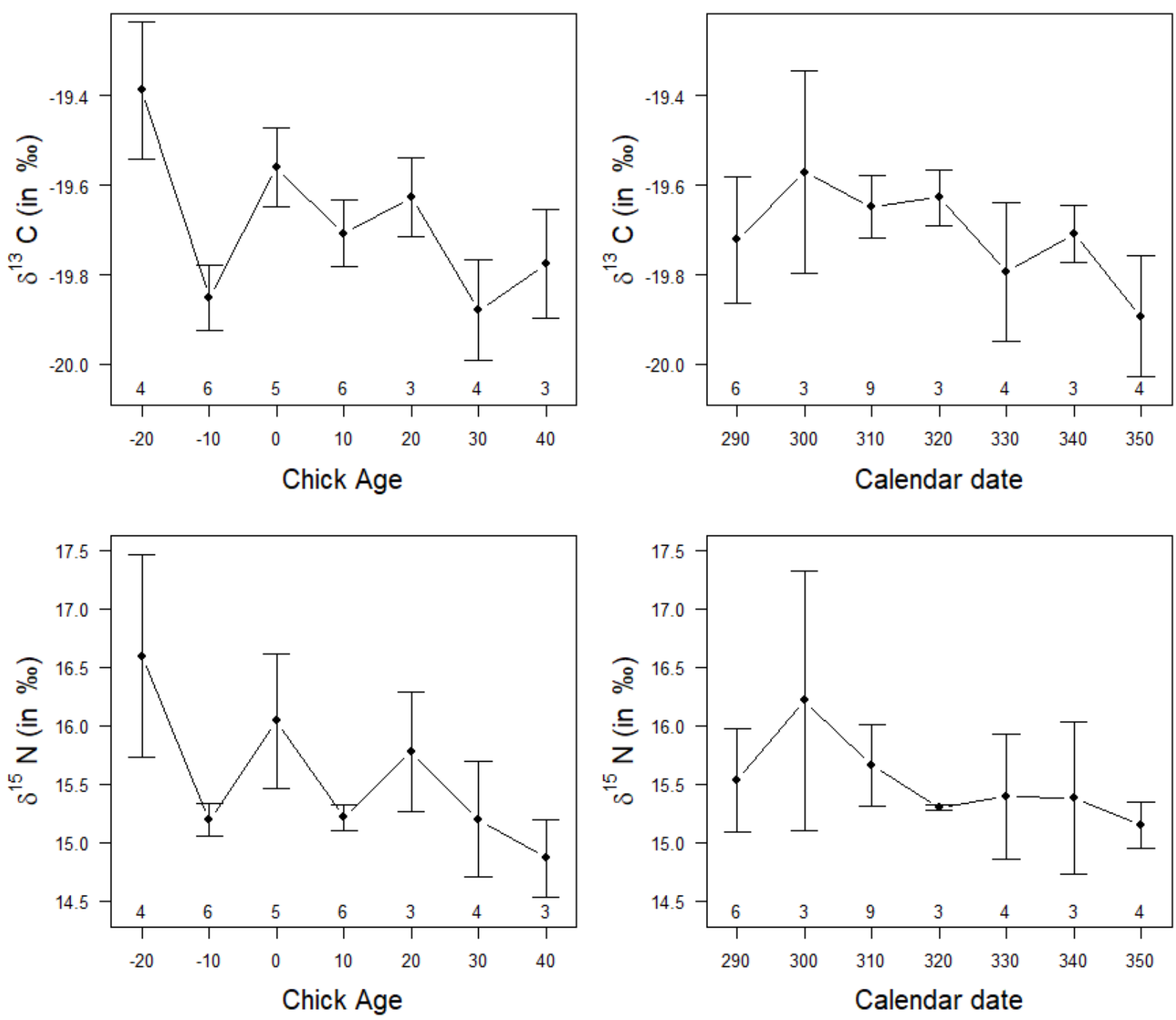

Figure 7 

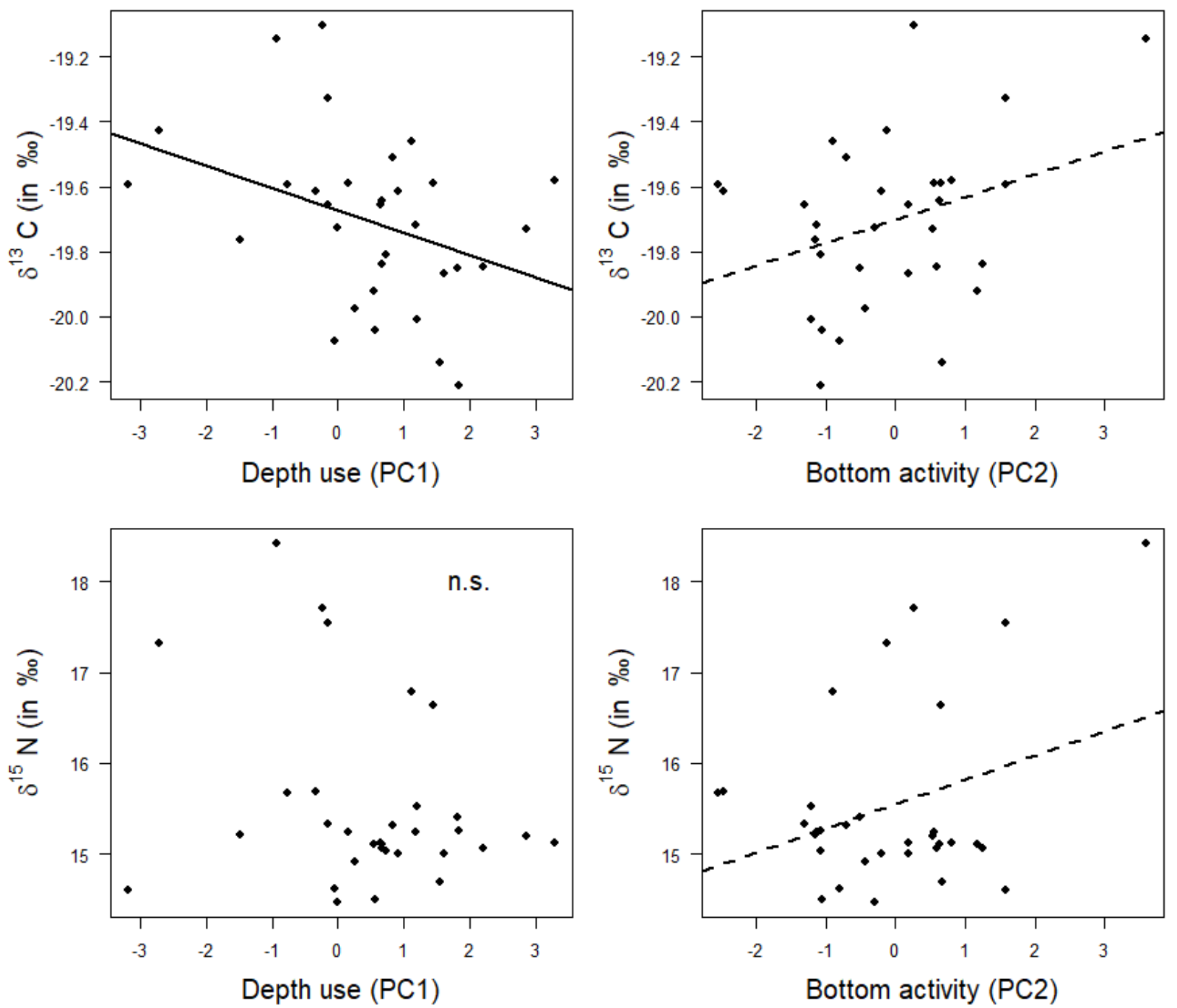

Figure 8

ESM1: Logger deployment summary 


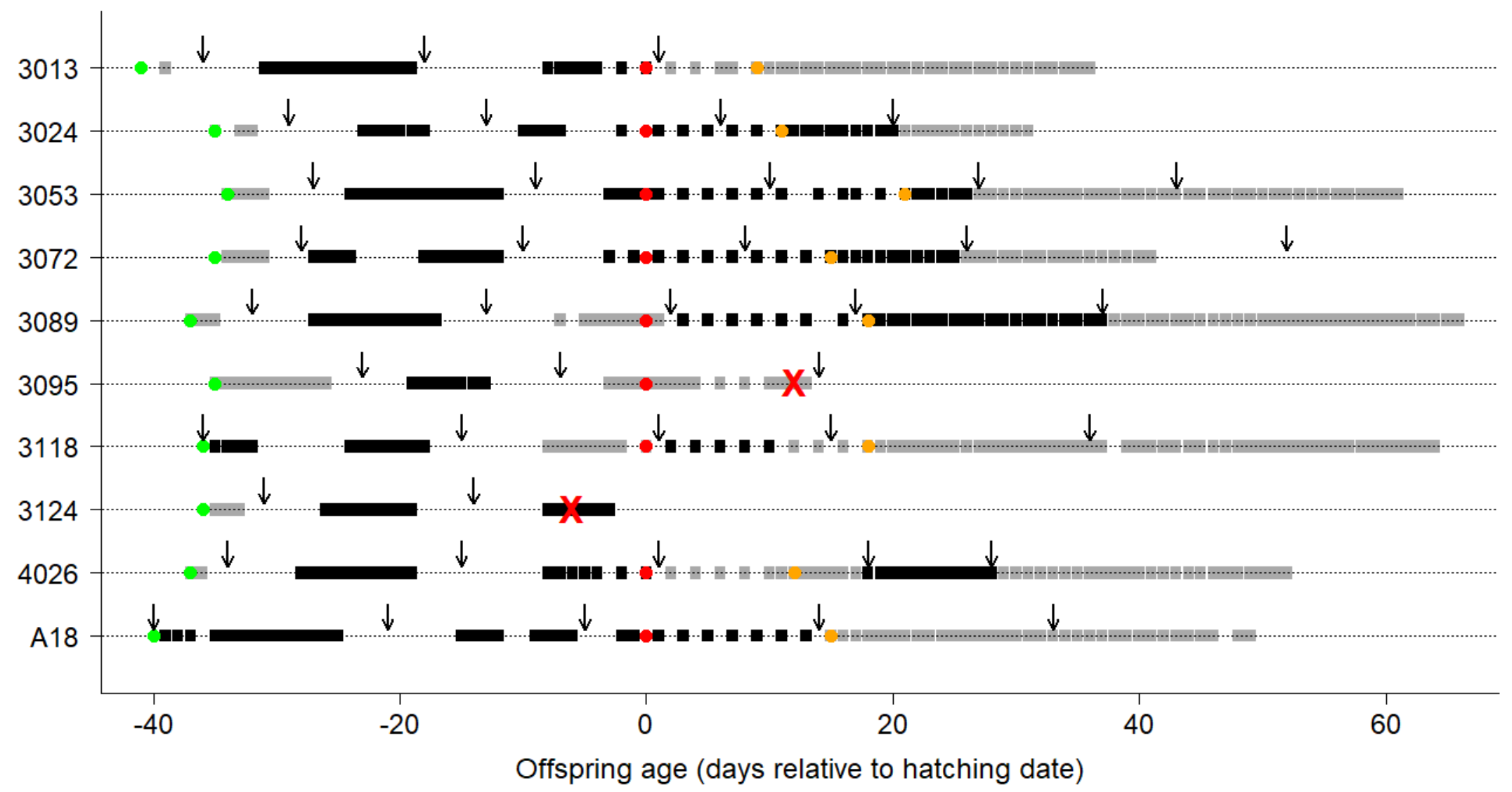

Fig. S1: Summary of trips recorded for each bird. One line corresponds to one bird with its identity on the y-axis. Green dot is the laying date (i.e. date of the first laid egg), red dot is the hatching date (i.e. date of the first hatched egg), orange dot indicates the start of post-guard stage (i.e. date when chicks are left alone during the day for the first time), and red cross is the date of failure (i.e. eggs found smashed or chicks found dead). Black rectangles represent trips at sea with logger data collected. Grey rectangles represent trips at sea without recordings. Time spent ashore is visible. Arrows represent penguin captures (for blood sampling and/or logger deployments). 


\section{ESM2: Results on all 12 diving parameters}

\section{Changes in diving parameters along the season:}

We examined the change of each of our 12 estimated diving parameters according to breeding stage (Fig. S2). As for the PCA, the variability in diving parameters was lower in guard than in the other two stages. Further, using post-hoc tests after a linear mixed model, we showed that penguins performed shorter and shallower but more frequent dives (also followed by a shorter post-dive recuperation) in post-guard than in the other two stages, confirming the decrease of depth use in post-guard highlighted in the PCA.

Further, we found that penguins performed a higher proportion of $U$ dives with lower bottom use and smaller number of undulations during guard than during incubation and post-guard (Fig. S2). This was confirmed by quadratic effects of calendar date or offspring age on these parameters (Figs. S3 and S4). Again, this confirms the lower bottom activity in guard revealed by the PCA.

Finally, the duration of diving activity increased along the season (higher in post-guard than guard than incubation, and linear increase with chick age or calendar date; Figs. S2, S3 and S4), probably in relation with the increase in day length. 

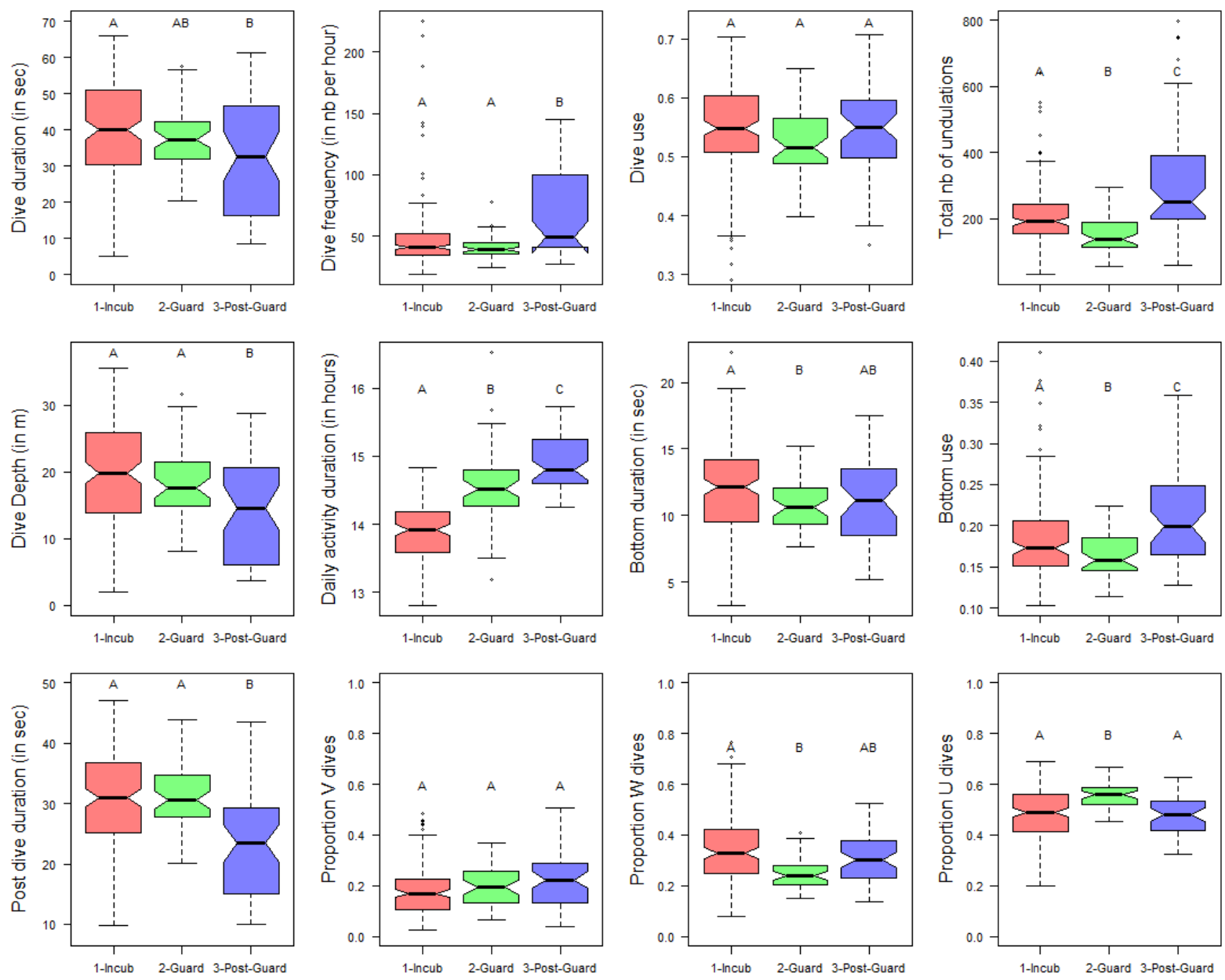

Fig. S2: Diving parameters according to breeding stages. Boxplots of daily values per breeding stage of dive duration (in sec), dive depth (in $\mathrm{m}$ ), post-dive duration (in sec), dive frequency (number of dives per hour of diving activity), daily activity duration (number of hours during which the individual dived), proportion of $V$ dives (proportion of dives with no bottom phase), dive use (ratio between dive duration and dive + post-dive duration), bottom duration (in seconds), proportion of $W$ dives (proportion of dives with undulations at the bottom), total number of undulations (cumulative number of undulations per day), bottom use (ratio between bottom duration and dive + post-dive duration), proportion of $U$ dives (proportion of dives with a bottom phase but no undulations). Marginal means with different letters are significantly different for $p<.05$ (Tukey HSD). 

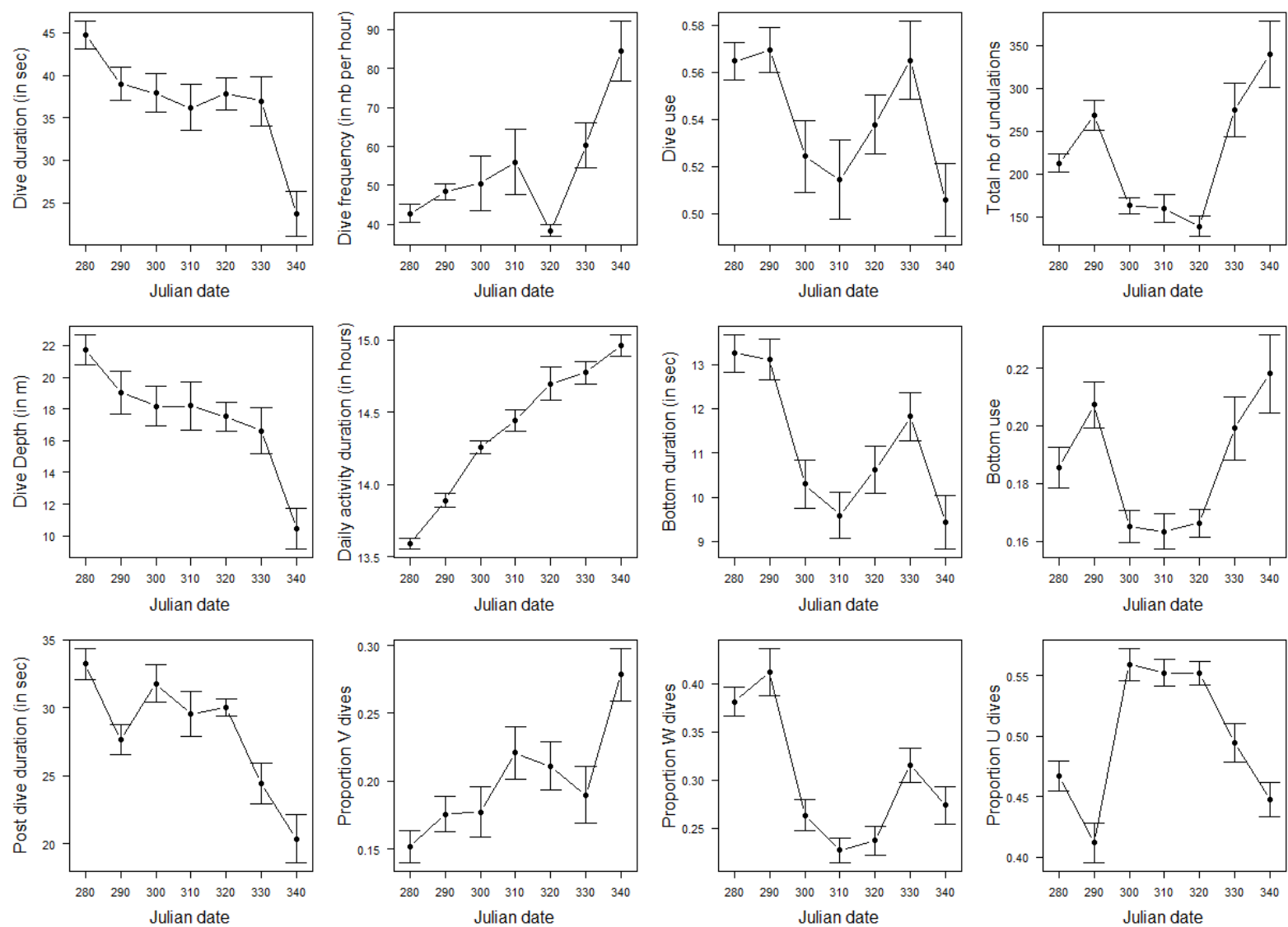

Fig. S3: Diving parameters along the season. Means $\pm S E$ of daily values according to calendar Julian date for dive duration (in sec), dive depth (in $\mathrm{m}$ ), post-dive duration (in sec), dive frequency (number of dives per hour of diving activity), daily activity duration (number of hours during which the individual dived), proportion of $V$ dives (proportion of dives with no bottom phase), dive use (ratio between dive duration and dive + post-dive duration), bottom duration (in seconds), proportion of $W$ dives (proportion of dives with undulations at the bottom), total number of undulations (cumulative number of undulations per day), bottom use (ratio between bottom duration and dive + post-dive duration), proportion of $U$ dives (proportion of dives with a bottom phase but no undulations). Calendar dates were binned in 10 day periods. Categories with less than 10 daily values are not represented here. 

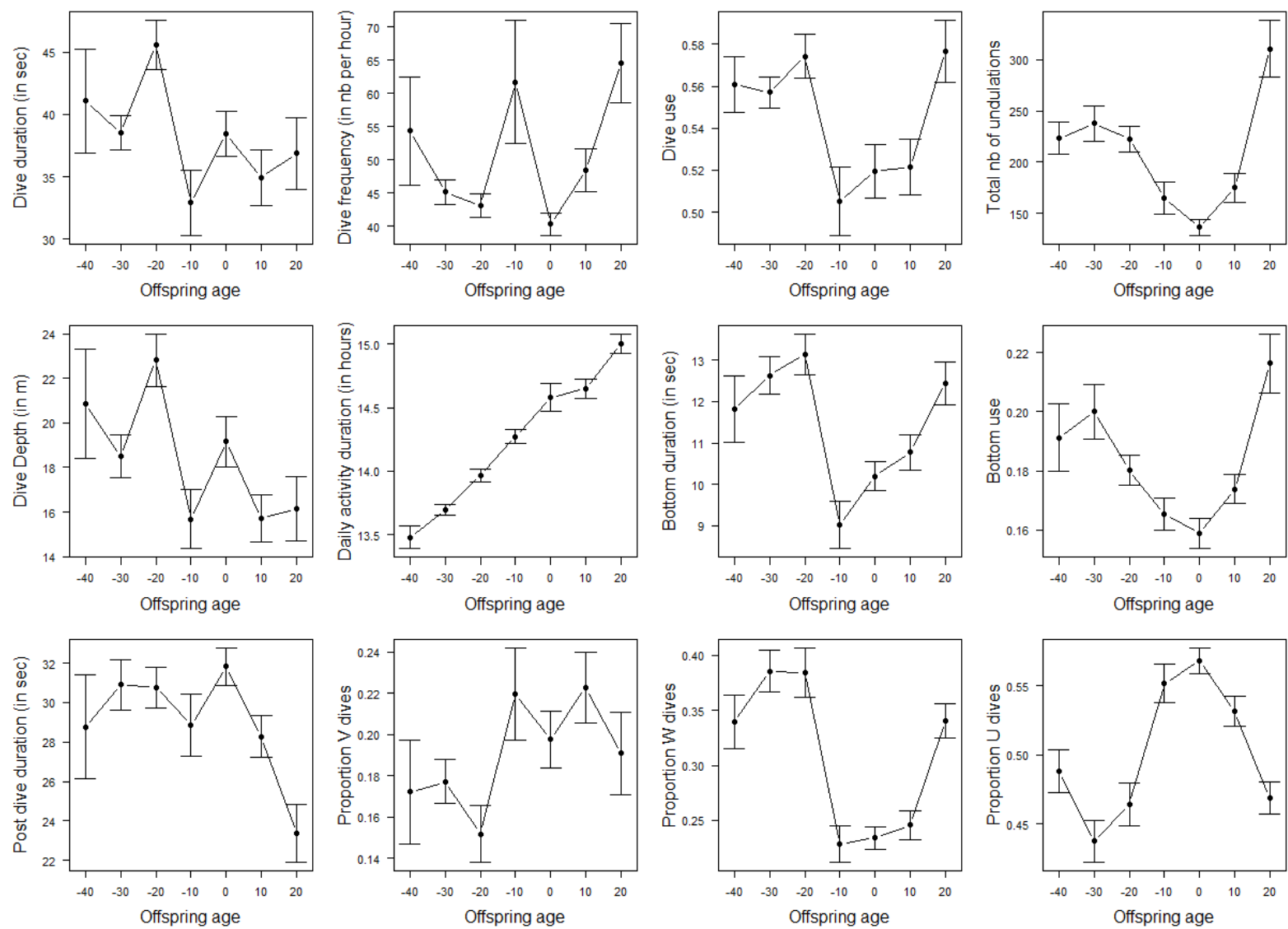

Fig. S4: Diving parameters according to offspring age. Means \pm SE of daily values according to offspring age for dive duration (in sec), dive depth (in $m$ ), post-dive duration (in sec), dive frequency (number of dives per hour of diving activity), daily activity duration (number of hours during which the individual dived), proportion of $V$ dives (proportion of dives with no bottom phase), dive use (ratio between dive duration and dive + post-dive duration), bottom duration (in seconds), proportion of $W$ dives (proportion of dives with undulations at the bottom), total number of undulations (cumulative number of undulations per day), bottom use (ratio between bottom duration and dive + post-dive duration), proportion of $U$ dives (proportion of dives with a bottom phase but no undulations). Offspring ages were binned in 10 day periods. Negative ages correspond to the incubation period (i.e. before egg hatching), while positive values correspond to chick age from hatching. Categories with less than 10 daily values are not represented here. 


\section{Interindividual differences in diving parameters:}

Differences between individuals are presented graphically on Fig. S5. For instance, 3095 dived deeper and longer due to a low proportion of V dives, while 3013 performed short shallow dives.
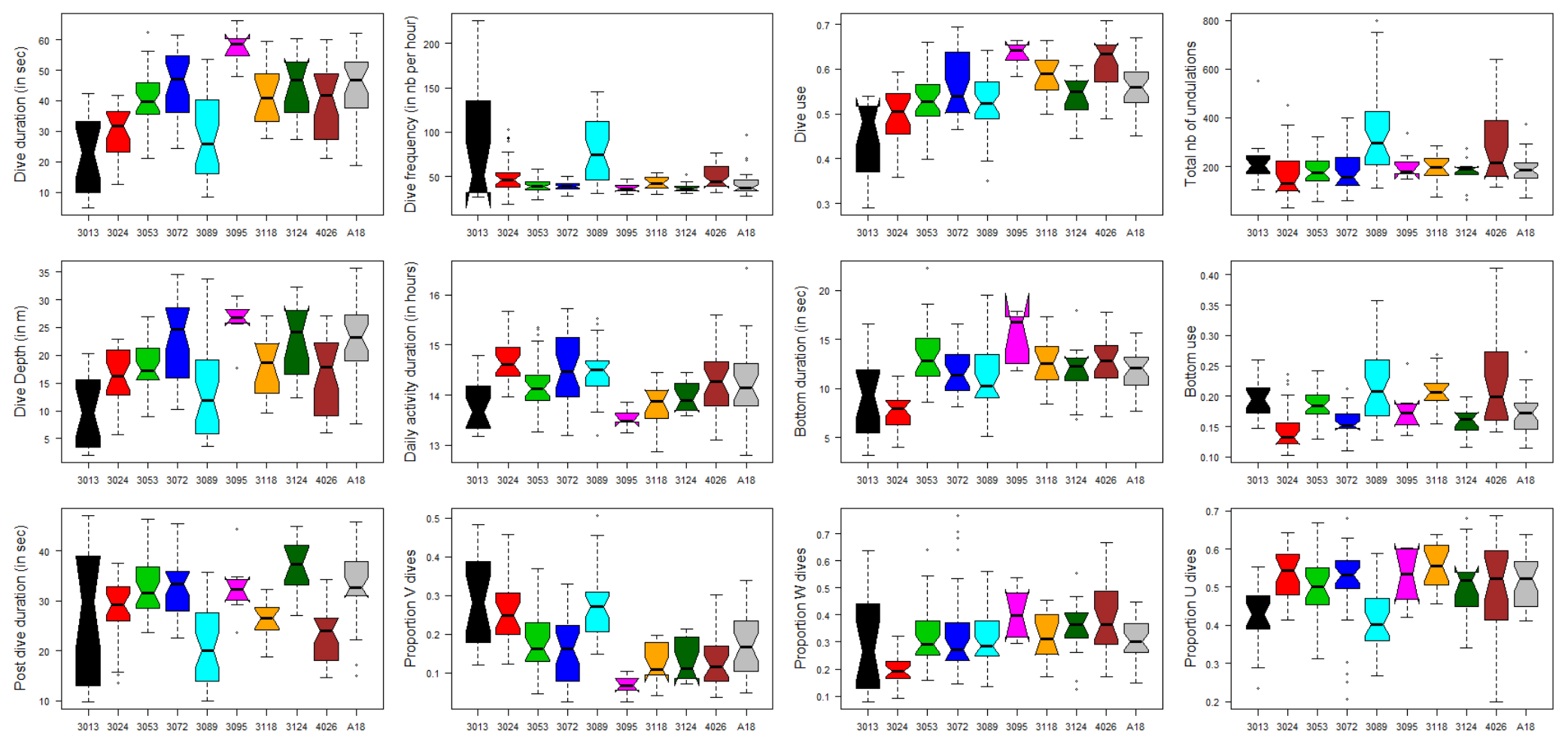

Fig. S5: Diving parameters according to individuals: Boxplots of daily values per individual of dive duration (in sec), dive depth (in m), post-dive duration (in sec), dive frequency (number of dives per hour of diving activity), daily activity duration (number of hours during which the individual dived), proportion of $V$ dives (proportion of dives with no bottom phase), dive use (ratio between dive duration and dive + post-dive duration), bottom duration (in seconds), proportion of $W$ dives (proportion of dives with undulations at the bottom), total number of undulations (cumulative number of undulations per day), bottom use (ratio between bottom duration and dive + post-dive duration), proportion of $U$ dives (proportion of dives with a bottom phase but no undulations). 
2 Using linear models, we tested whether $\delta^{13} \mathrm{C}$ values could be explained by diving parameters averaged 3 over the 28 previous days (Fig. S6). $\delta^{13} \mathrm{C}$ values decreased with dive duration, depth, post-dive duration 4 and daily activity duration. On the contrary, it increased with bottom use and tended to increase with the 5 number of undulations performed. This confirms what we found with the PCA, i.e. that $\delta^{13} \mathrm{C}$ values 6 increased with bottom activity and decrease with depth use. Further, using linear mixed effect models to account for interindividual differences, all but one relationships (effect of dive frequency not significant 8 anymore) were retained, suggesting that the effects of these parameters on $\delta^{13} \mathrm{C}$ values were not only 9 related to interindividual differences.
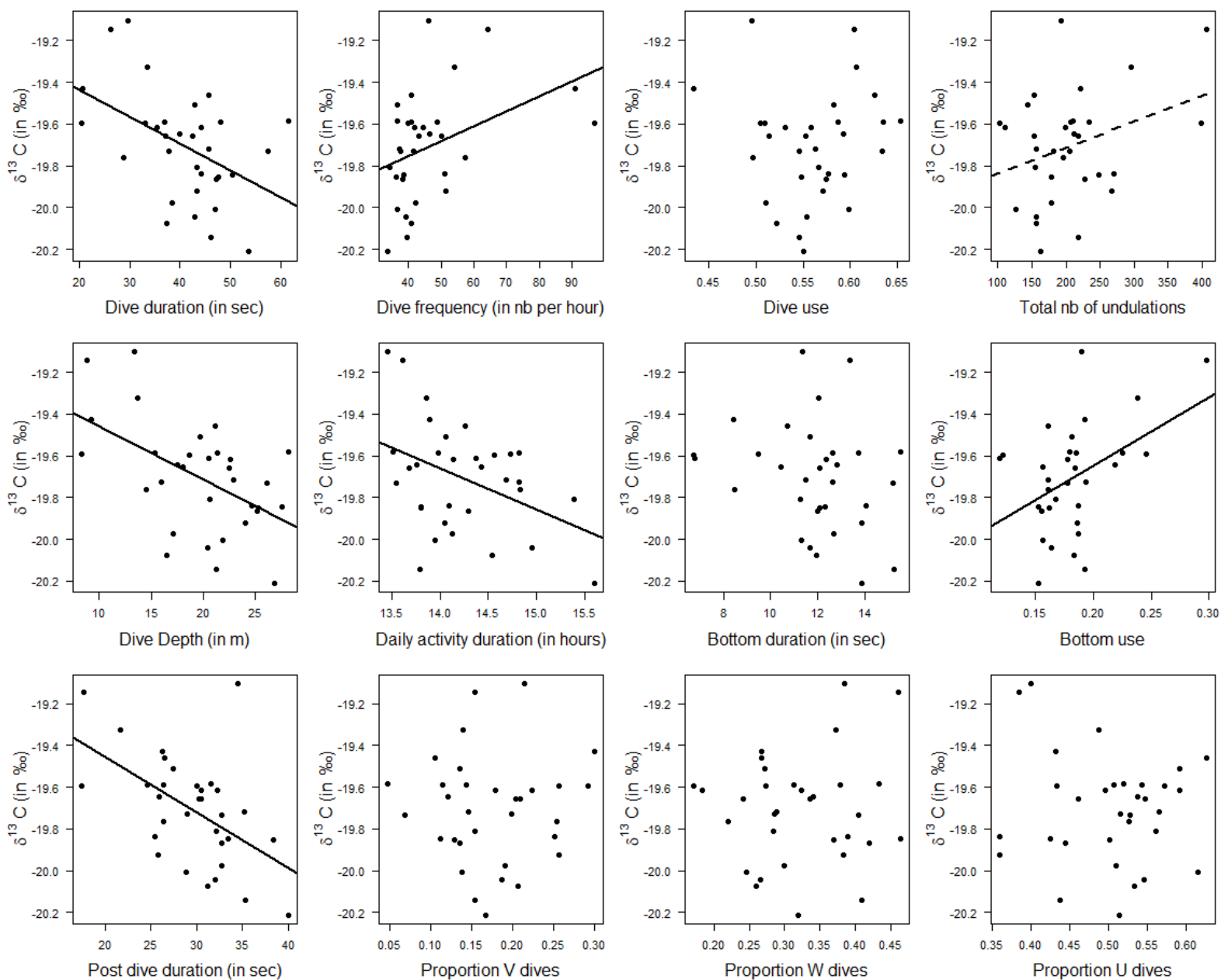

Fig. S6: Stable isotope carbon values in whole blood according to diving patterns. $\delta^{13} C$ values according to dive duration (in sec), dive depth (in $\mathrm{m}$ ), post-dive duration (in sec), dive frequency (number of dives per hour of diving activity), daily activity duration (number of hours during which the individual dived), proportion of $V$ dives (proportion of dives with no bottom phase), dive use (ratio between dive duration and dive + post-dive duration), bottom duration (in seconds), proportion of $W$ dives (proportion of dives 
with undulations at the bottom), total number of undulations (cumulative number of undulations per day), bottom use (ratio between bottom duration and dive + post-dive duration), proportion of $U$ dives (proportion of dives with a bottom phase but no undulations). Because isotopic values in whole blood represent the diet and physiology of the penguins in the previous 4 weeks, diving parameter values are the average of daily values over the 28 days previous to blood sample. The solid line indicates a significant relationship between $\delta^{13} C$ values and diving parameters, while dashed lines represent trends $(P=0.06)$.

Using linear models, we tested whether $\delta^{15} \mathrm{~N}$ values could be explained by diving parameters averaged over the 28 previous days (Fig. S7). Similarly to $\delta^{13} \mathrm{C}$ values, $\delta^{15} \mathrm{~N}$ values decreased with dive duration, depth, post-dive duration and tended to decrease with daily activity duration. This suggests a stronger connection of $\delta^{15} \mathrm{~N}$ values with depth use than shown with the PCA. On the contrary, it increased with bottom use, confirming PCA results, i.e. that $\delta^{15} \mathrm{~N}$ values tended to increase with bottom activity. Further, using linear mixed effect models to account for interindividual differences, none of the relationships were retained, suggesting that the effects of these parameters on $\delta^{15} \mathrm{~N}$ values were related to interindividual differences, as suggested by the PCA results.
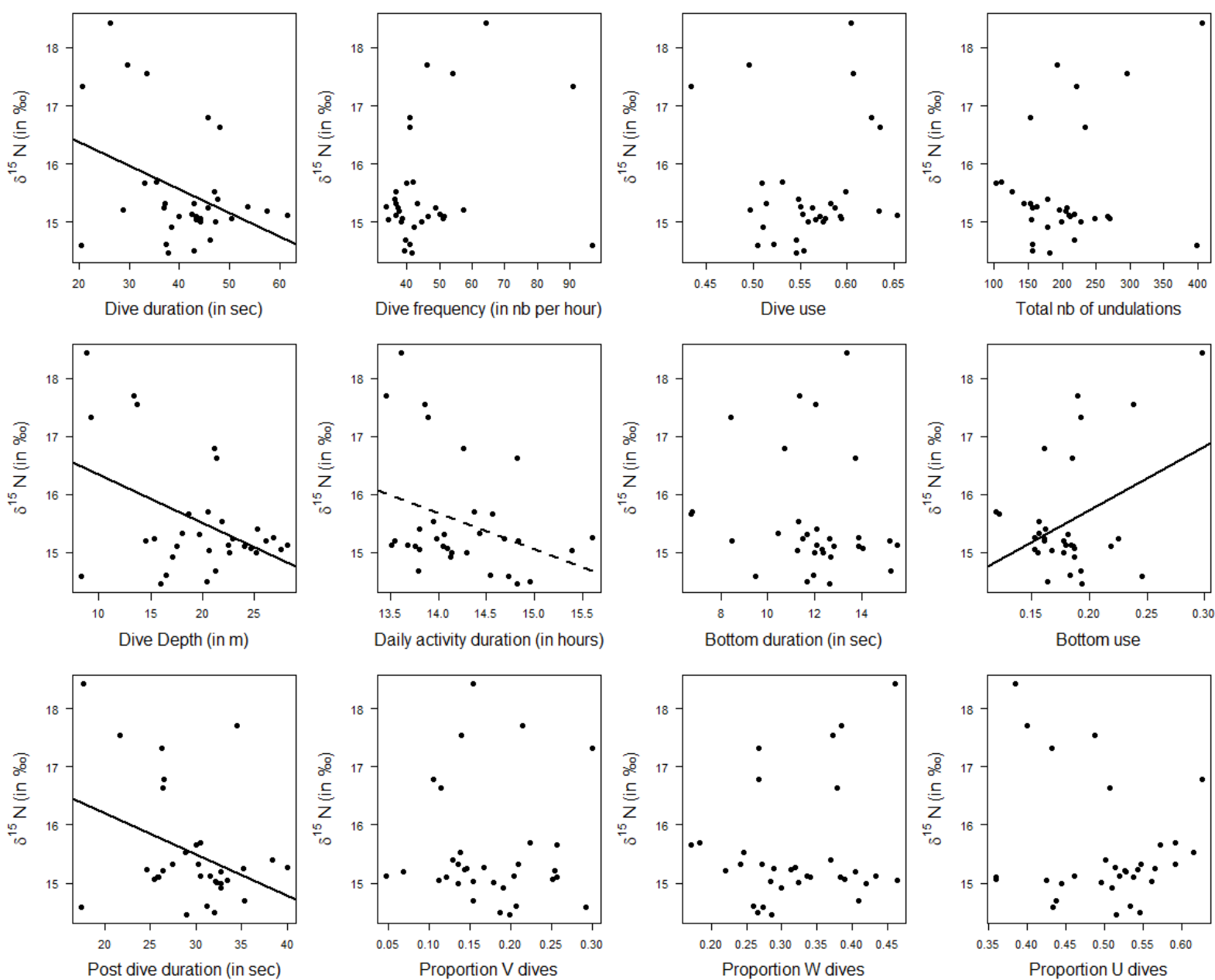

Fig. S7: Stable isotope nitrogen values in whole blood according to diving patterns. $\delta^{15} N$ values according to dive duration (in sec), dive depth (in $\mathrm{m}$ ), post-dive duration (in sec), dive frequency (number 
33 of dives per hour of diving activity), daily activity duration (number of hours during which the individual

34 dived), proportion of $V$ dives (proportion of dives with no bottom phase), dive use (ratio between dive

35 duration and dive + post-dive duration), bottom duration (in seconds), proportion of $W$ dives (proportion

36 of dives with undulations at the bottom), total number of undulations (cumulative number of undulations

37 per day), bottom use (ratio between bottom duration and dive + post-dive duration), proportion of $U$ dives

38 (proportion of dives with a bottom phase but no undulations). Because isotopic values in whole blood

39 represent the diet and physiology of the penguins in the previous 4 weeks, diving parameter values are the

40 average of daily values over the 28 days previous to blood sample. The solid line indicates a significant

41 relationship between $\delta^{15} N$ values and diving parameters, while dashed lines represent trends $(P=0.06)$. 
44 ESM3: Changes in diving strategies with offspring age rather than julian calendar dates

\section{Changes in diving strategies with offspring age}

49 Depth use index (PC1) decreased with the offspring age (LMM: $\mathrm{n}=243, \mathrm{~N}=10$ males, $-0.03 \pm 0.01, \mathrm{P}$ $50<0.001$, Figure 3B). In other words, penguins dived more frequently with a higher proportion of short and

51 shallower $\mathrm{V}$ while the offspring aged. We observed a quadratic effect of offspring age on bottom activity 52 index (LMM: $\mathrm{n}=243, \mathrm{~N}=10$ males, $0.002 \pm 0.000, \mathrm{P}<0.001$, Figure 3E), with lower values around 53 hatching. This means that birds performed a higher proportion of $U$ dives with a low bottom use and low 54 number of undulations just before hatching and during guard. 